\title{
Circulação de anticorpos contra o vírus amarílico em população simiana da região da Usina Hidrelétrica de Porto Primavera, São Paulo, Brasil.
}

\author{
Maura Antônia Lima
}

Dissertação apresentada ao Programa de Pós-Graduação em Saúde Pública para a obtenção do título de Mestre em Saúde Pública.

Área de Concentração: Serviços de Saúde Pública

Orientador: Profa. Dra. Nicolina Silvana Romano-Lieber

\section{São Paulo}

2006

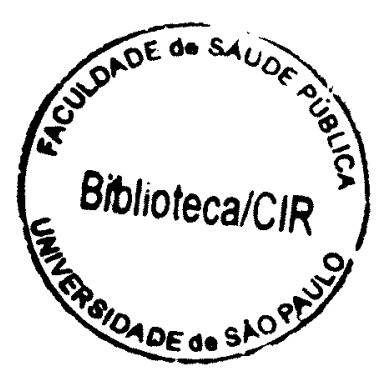


Agradeço...

"A Deus pelo imenso dom da vida e pelas" "Valiosas oportunidades concedidas". 
Dedico...

À Minha filha INGrid Valéria Lima PORTo,

Pois, o fato de você existir me anima a buscar meu aprimoramento.

É por você que sigo em frente, superando as dificuldades inerentes à vida. 
"Se pude enxergar mais ao longe foi porque subi nos ombros de gigantes".

(Isaac Newton) 


\section{AGRADECIMENTOS}

A Prof. Dra. Nicolina Silvana Romano-Lieber, agradeço pela orientação, apoio, incentivo e confiança na minha capacidade, os quais foram pontos fundamentais para que este trabalho fosse realizado.

Ao Prof. Dr. Almério de Castro Gomes, pelo incentivo e ajuda no início da minha carreira, pelas preciosas criticas sugestões e contribuições feitas ao projeto.

A Ana Maria Duarte, Izilda Curado e Maria Dulce Bianchi Rosa, agradeço pela amizade sincera, pela agradável convivência nesses anos. A vocês, só tenho que agradecer pela constante confiança, incentivo, estímulo e ajuda. Compartilho com vocês esta vitória. Muito Obrigado!

A Rosely dos Santos Malafronte pelo fornecimento de materiais e ajuda para que esse trabalho fosse concretizado.

Ao Prof. Dr. Luiz Tadeu de Moraes Figueiredo pelo fornecimento dos antígenos de febre amarela e por toda atenção que recebi enquanto estive em Ribeirão Preto.

A Soraya Biomédica do Laboratório de Virologia da FMUSP em Ribeirão Preto, pela amizade, carinho, atenção e colaboração no inicio deste o inicio deste projeto.

A Dra Rita Maria Ribeiro Nogueira, Chefe do Laboratório de Flavivírus (Fiocruz) pelo soro controle positivo de macaco, material necessário e imprescindível para que as análises deste projeto fossem realizadas .

Cleide Consalez pela colaboração e sugestões na escolha da metodologia utilizada neste trabalho. 
A Marcia Bicudo de Paula, Bióloga do Laboratório de Entomologia da FSP-USP por toda colaboração, sugestões e ajuda que recebi de você até este momento.

A Byanca Regina Paiva, Adriana Yurika Maeda e Ana Maria Marassá pela amizade, carinho, apoio e incentivo durante esta caminhada.

Ao Cecovisa (Centro Colaborador de Vigilância Sanitária) que financiou as passagens para realização de estágio em Ribeirão Preto.

Aos funcionários da CESP (Companhia Energética de São Paulo) das Unidades de Porto Primavera e Presidente Epitácio, em especial ao Dr. Lúcio de Oliveira e Souza, chefe da divisão veterinária.

Aos meus amigos do laboratório de Entomologia: Marcelo, Luis Filipe, Edna Bueno, Márcia Gutierrez, Paulo Roberto Urbinatti e Walter Ceretti Jr. pela amizade e carinho.

A todos os funcionários da Faculdade de Saúde Pública, do Departamento de Epidemiologia e do Departamento de Praticas de Saúde Publica.

A todos os amigos do dia a dia, de ontem e de sempre, que intercederam para que este trabalho fosse concluído ou que de alguma forma colaboraram para sua elaboração. 


\section{RESUMO}

LIMA MA. Circulação de anticorpos contra o vìrus amarílico em população simiana da região da Usina Hidrelétrica de Porto Primavera, São Paulo. [Dissertação de Mestrado - Faculdade de Saúde Pública - USP]. 2006

Introdução - A febre amarela (FA) é uma doença infecciosa de origem viral transmitida por mosquitos. O vírus da FA mantém-se em dois ciclos básicos: um ciclo urbano do tipo homem-mosquito e um ciclo silvestre onde o vírus é mantido por meio da infecção de macacos e da transmissão transovariana nos mosquitos. Assim, é necessária uma vigilância ativa sobre as populações de primatas não humanos, a fim de detectar a circulação do vírus amarilico, quando ainda está restrito a uma epizootia, bem como determinar, pela presença de anticorpos, uma possível circulação de vírus em regiões consideradas indenes ou de transição para a doença. Objetivo - padronizar o teste imunoenzimático ELISA (Enzyme Linked Immunosorbent Assay) para verificar a prevalência de anticorpos da classe IgG para o vírus da FA em soros de bugios (Alouatta caraya) que habitam a região do reservatório da Usina Hidrelétrica de Porto Primavera, SP. Resultados - O teste ELISA foi padronizado utilizando-se conjugado comercial anti-macacos e foi utilizado para testar amostras de 570 macacos. Nenhuma amostra testada foi reativa para a presença de anticorpos contra o vírus da FA. Conclusões - Os resultados são coerentes com a epidemiologia da FA na região. Mesmo sendo considerada área de transição não se conhece, até o momento, ocorrência de epizootia ou surto de FA na 
população humana da área e investigações entomológicas não tem apontado a presença de vetores de FA. O teste mostrou-se sensível, rápido e útil para a vigilância epidemiológica da doença. Além da observação da circulação viral nos macacos é necessária a vigilância entomológica de vetores da doença para a tomada de medidas de prevenção, como vacinação.

Descritores: Febre amarela; Arbovírus; ELISA; Macacos; Reservatórios; Vigilância epidemiológica. 


\section{ABSTRACT}

LIMA MA. Circulation of yellow fever virus antibodies in a simian population in the Porto Primavera Hydroelectric Plant region, in São Paulo. [Master's Degree Dissertation - College of Public Health - USP]. 2006

Introduction - Yellow fever $(\mathrm{YF})$ is an infectious viral disease transmitted by mosquitoes. The YF virus maintains itself in two basic cycles: an urban, manmosquito-type cycle and a wild cycle, in which the virus is maintained through the infection of monkeys and transovarian transmission in mosquitoes. Thus, active surveillance of non-human primate populations is required to detect yellow fever virus circulation while it is still epizootic and to determine, through the presence of antibodies, possible virus circulation in regions that are considered either exempt of or transitional for the disease. Objective - standardize the ELISA (Enzyme Linked Immunosorbent Assay) to check the prevalence of IgG-class antibodies against the YF virus in the sera of monkeys (Alouatta caraya) that inhabit the Porto Primavera Hydroelectric Plant reservoir region, in São Paulo. Results - The ELISA test was standardized using a commercial anti-monkey conjugate to test samples collected from 570 monkeys. None of the tested samples were reactive to the presence of YF virus antibodies. Conclusions - The results are coherent with the YF epidemiology in the region. Even though it is considered a transition area, thus far no YF epizootic occurrence or outbreak among the human population has been reported in the area 
and entomological investigations have not pointed to the presence of YF vectors there. The test revealed to be very sensitive, fast, and useful for the disease's epidemiological surveillance. Besides the viral circulation in the reservoirs, it is necessary an entomological surveillance on the vectors to take measures of prevention, as vaccination.

Key words: Yellow fever; Arbovirus; ELISA; Monkeys; Reservoirs; Epidemiological surveillance. 


\section{Índice}

1 Introdução 1

1.2 Os macacos e a ocorrência de Epizootias 5

$\begin{array}{llr}1.3 & \text { Justificativa } & 8\end{array}$

$\begin{array}{lll}2 \text { Objetivos } & 10\end{array}$

$\begin{array}{lll}2.1 & \text { Objetivo Geral } & 10\end{array}$

$\begin{array}{lll}2.2 & \text { Objetivo Específico } & 10\end{array}$

3 Materiais e Métodos 11

$\begin{array}{lll}3.1 & \text { Área de Estudo } & 11\end{array}$

3.2 Período de Estudo 14

$\begin{array}{ll}3.3 & \text { Coleta de sangue de macacos } \\ \end{array}$

$\begin{array}{lll}3.4 & \text { Teste Imunoenzimático de ELISA } & 17\end{array}$

3.5 Preparo dos Reagentes 19

3.5.1 Fluido ascítico Imune de Febre Amarela $\quad 19$

3.5.2 Antígeno de Febre Amarela 19 
4.1 4.1 Padronização da reação enzimática para pesquisa de anticorpos da classe

IgG em soros de macacos

4.2 4.2 Pesquisa de anticorpos para febre amarela em soros de macacos

5 Discussão

5.1 5.1 Sobre a padronização da reação Imunoenzimática de Elisa

5.2 5.2 Sobre padronização da reação enzimática para pesquisa de anticorpos da classe IgG em soros de macacos.

6 Conclusões 


\section{ANEXOS}

Anexo 1 - Mapa com municípios de casos confirmados e de epizootias de febre amarela no Brasil, 2003.

Anexo 2 - Mapa com municípios de casos confirmados e de epizootias de febre amarela no Brasil, 2004.

Anexo 3 - Municípios com casos de Febre Amarela Silvestre e Epizootias, no Brasil, durante o ano de 2004.

Anexo 4 - Áreas de Risco para Febre Amarela Silvestre no Brasil.

Anexo 5 - Carta de autorização da CESP para uso das amostras de macacos.

Anexo 6 - Padronização da concentração de fluído ascítico anti-febre. amarela, utilizando soro controle positivo humano

Anexo 7 - Padronização da concentração de fluído ascítico anti-febre amarela, utilizando soro controle negativo humano.

Anexo 8 - Titulação do conjugado Anti-Humano utilizando soro controle positivo humano para febre amarela.

Anexo 9 - Titulação do conjugado Anti-Humano utilizando soro controle negativo humano para febre amarela.

Anexo 10 - Reação de ELISA para pesquisa de anticorpos para febre amarela em soros humanos de pessoas vacinadas ( 1 ao 8 ) e pessoas não vacinadas (9 ao 12) contra o vírus amarílico.

Anexo 11 - Reagentes utilizados na reação de ELISA 
Anexo 12 - Materiais utilizados na reação de ELISA

Anexo 13 - Resultados da sorologia de macacos 


\section{INTRODUÇÃO}

A febre amarela é uma doença infecciosa não contagiosa, de origem viral, que se mantém endêmica ou enzoótica nas florestas tropicais da América do Sul e da África causando periodicamente surtos isolados ou epidemias de grande impacto em

Saúde Pública. É transmitida ao homem por picada de insetos hematófagos da família Culicidae, pelos gêneros Aedes e Haemagogus (MONATH, 2001; TESH, 2001).

O vírus da febre amarela faz parte grupo dos arbovírus (do inglês arthropod borne vírus) e pertence ao gênero Flavivirus (Flaviviridae) (WESTAWAY, 1985).

Este gênero é o mesmo de outros vírus responsáveis por causar doenças no homem, entre os quais os vírus do Nilo Ocidental, Dengue, Rocio e da Encefalite de São Luís (VASCONCELOS, 2003).

Não se sabe se a Febre Amarela já existia no Novo Mundo antes das viagens de Cristóvão Colombo. Algumas evidências levam a crer que tenha sido introduzida na América Tropical através dos navios que faziam tráfico de escravos. Presume-se que a epidemia febril que atacou os conquistadores espanhóis na Península de Yucatan, em 1648, tenha sido febre amarela (FUNASA, 1999).

As tripulações dos barcos que navegavam pelas rotas transatlânticas e costeiras em águas equatoriais constituíam uma fonte permanente de vítimas com o vetor se adaptando à vida de bordo, utilizando os recipientes de água doce como local de proliferação. Dessa maneira, a febre amarela se transformou na "praga dos mares", fazendo vítimas em praticamente todos os portos que recebiam essas embarcações (FUNASA, 1999). 
Durante os séculos XVIII e XIX, “a febre amarela foi o maior flagelo das regiões tropicais, fazendo inúmeras incursões pelas zonas temperadas dos hemisférios boreal e austral, de tal modo que não há região no continente americano que não tenha sido invadida, desde o sul, da Argentina ao Chile, até o norte, no Canadá" (SOPER, 1942).

Por muitos anos acreditou-se que a febre amarela era transmitida através de miasmas, do desenvolvimento espontâneo da doença nos navios negreiros e outras teorias. A descoberta de que um mosquito estava associado à transmissão da doença ocorreu quando experiências realizadas com voluntários pelo médico cubano Carlos Juan Finlay, verificaram a inter-relação homem-vetor, trazendo a luz ao conhecimento da comunidade cientifica internacional em Washington, EUA (MENDEZ, 1983).

A doença apresenta-se sob duas formas epidemiológicas distintas: a Febre Amarela Urbana e Febre Amarela Silvestre, semelhante do ponto de vista etiológico, fisiopatológico, imunológico e clínico. As diferenças estão relacionadas ao vetor envolvido no ciclo de transmissão, tipo de hospedeiro vertebrado e do local de ocorrência (MONATH, 1988, 2001).

No ciclo urbano da febre amarela a transmissão do vírus é feita diretamente ao homem pelo vetor Aedes aegypti. O próprio homem infectado e em fase virêmica atua como amplificador e disseminador do vírus na população. Uma vez introduzido o vírus no ambiente urbano, a pessoa infectada desenvolverá viremia, podendo expressar a doença e servir de fonte de infecção a novos mosquitos (VASCONCELOS, 2000). 
Assim o ciclo se perpetua, até que se esgotem os suscetíveis ou se realize vacinação da população. No Brasil, este ciclo não ocorre desde 1942 (VASCONCELOS, 2000).

Figura 1 - Ciclo da Febre Amarela.

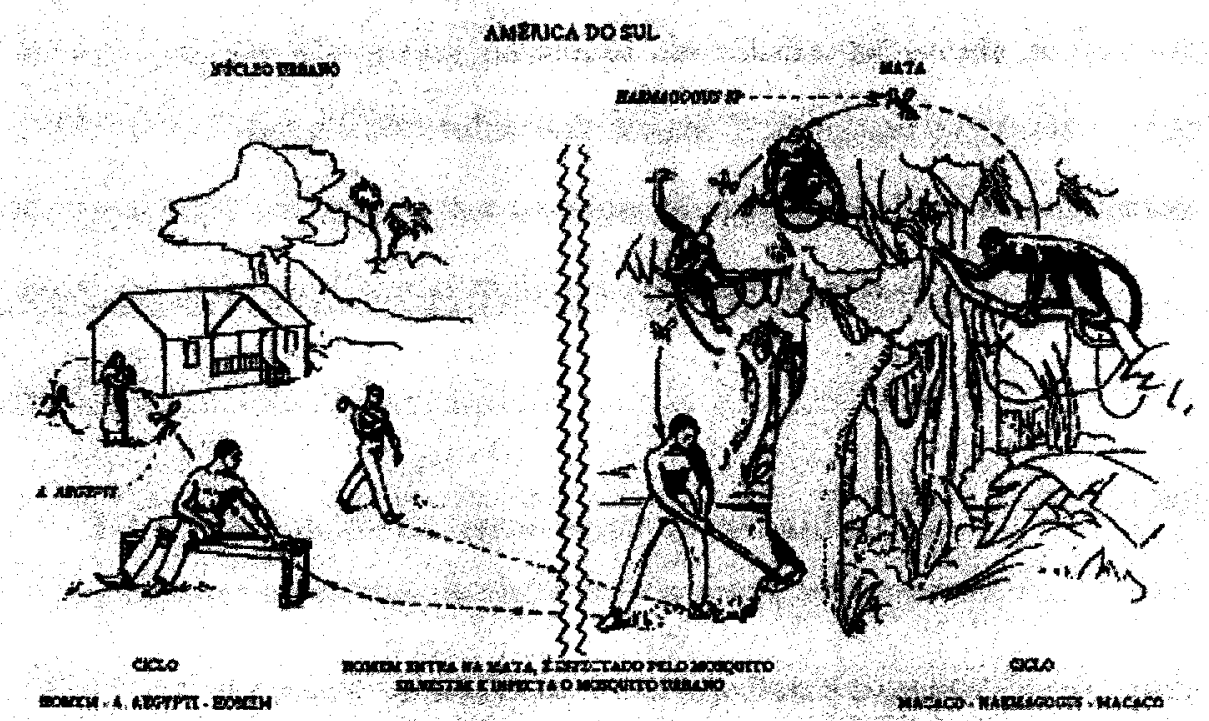

Fonte: adaptado da BENCHIMOL 2001 p. 149

O ciclo silvestre da doença é complexo. Foi reconhecido desde a década de 1930, porém pouco compreendido e varia de acordo com a região em que ocorre (VASCONCELOS, 2000, 2003).

Na África, os mosquitos responsáveis pela transmissão desse ciclo são do gênero Aedes e na América do Sul, algumas espécies de Haemagogus e Sabethes. Os mosquitos são transmissores do vírus e, uma vez infectados, permanecem assim durante sua longevidade (VASCONCELOS, 2000, 2003). 
Os casos de febre amarela silvestre em humanos ocorrem de forma acidental, quando uma pessoa não vacinada entra em regiões onde há circulação do agente (VASCONCELOS, 2000, 2003).

Os macacos são hospedeiros amplificadores do vírus entre as populações de mosquitos e podem desenvolver uma viremia de duração entre dois a seis dias (BUGHER, 1951). Tanto os macacos quanto o homem ao se infectarem podem morrer ou se curar, adquirindo imunidade (SOPER, 1936; TAYLOR, 1951; WHO, 1985).

A vacina de febre amarela vem sendo utilizada no Brasil desde 1937, no entanto, ocorrem registros de casos esporádicos em populações rurais não imunes, em decorrência do ciclo silvestre de transmissão da doença (FÉ et al., 2003).

Torna-se preocupante a possibilidade da reemergência do ciclo urbano da doença, uma vez que as condições climáticas são propícias à proliferação do mosquito Ae. Aegypti, acrescida da falta de medidas de combate a esse vetor em algumas regiões, à dificuldade operacional para desenvolver ações de vigilância e ao custo crescente dessas medidas (FUNASA, 2004).

Observa-se um crescimento demográfico nas zonas enzoóticas, regiões com baixa cobertura vacinal, além da reintrodução e dispersão do Ae. aegypti na quase totalidade dos países nos quais havia sido erradicado, inclusive em regiões de altitudes elevadas e zonas rurais da Colômbia, onde antes nunca havia sido encontrado (FUNASA, 2004).

No Brasil, as áreas de risco para febre amarela silvestre incluem as regiões Norte, Centro-Oeste, o estado do Maranhão e mais a parte ocidental dos estados da 
Bahia, Minas Gerais, São Paulo, Paraná, Santa Catarina e Rio Grande do Sul (VASCONCELOS, 2002).

Nessas áreas, a doença ocorre principalmente entre lenhadores, seringueiros, vaqueiros, garimpeiros, caçadores, ribeirinhos dos rios amazônicos e em praticantes do turismo ecológico (MONATH, 1987, 1988), com maior frequiência em pessoas do sexo masculino com idade entre 14 e 35 anos, devido a maior exposição (VASCONCELOS, 2000, 2001).

A maior ocorrência da doença é observada no período de chuvas, entre os meses de janeiro a abril, quando a densidade vetorial é elevada, coincidindo com a época de maior atividade agrícola (VASCONCELOS, 1997, 2000, 2001).

\section{2 Os Macacos e a ocorrência de Epizootias}

O gênero alouatta (Lacépède, 1799) é um dos cinco gêneros que compõem a Família Atelidae (RYLANDS et al., 2000). Entre os primatas neotropicais, é o gênero mais amplamente distribuído. São encontrados desde o México até a Argentina (NEVILLE et al., 1988).

Esse gênero é representado por nove espécies (RYLANDS et al., 2000).

No Brasil, são encontradas apenas quatro espécies: Alouatta seniculus, Alouatta belzebul, Alouatta caraya e Alouatta guariba (HIRSCH et al., 1991) sua ocorrência é registrada em regiões da Floresta Amazônica, Mata Atlântica, Cerrado, 
Caatinga e Mata de Araucária (SANTAMARIA-GÓMEZ, 1999; BONVICINO, 1989, GUEDES et al., 2000; AURICCHIO, 1995).

Os alouatta são animais grandes, podem pesar de 6 a $10 \mathrm{~kg}$, possuem cauda longa e preênsil (AURICCHIO, 1995). Possuem hábito arbóreo, sua alimentação é composta de folhas, brotos e frutos, apresentam locomoção lenta, vivem em grupos sociais com um macho líder e várias fêmeas, vivem em grupos, com um número médio de três a sete indivíduos, mas que pode variar dependendo da espécie ou da qualidade do ambiente (KINZEY, 1997; PINTO et al., 1993).

Os machos vocalizam para determinar a localização do grupo e para defender seu território (NEVILLE et al., 1988).

$\mathrm{Na}$ África e nas Américas, os primatas não humanos são os principais hospedeiros do vírus amarílico (na forma silvestre). As espécies mais freqüentemente implicadas na transmissão deste vírus pertencem aos gêneros Cebus, Alouatta e Callithrix (DAVIS \& SHANNON, 1929; DAVIS, 1930; BENSABATH et al., 1966; LAEMMERT \& KUMM, 1950, ANDERSON \& DOWNS, 1955; LAEMMERT \& FERREIRA, 1945; LAEMMERT et al., 1946).

Enquanto que na África os símios apresentam uma maior resistência à infecção pelo vírus da febre amarela, raramente sucumbindo à doença, nas Américas os macacos mostram-se mais sensíveis e, quando ocorre infecção, esta é de alta letalidade para as espécies de primatas neotropicais (WOLFE et al., 2001).

Como exceção tem-se a espécie Cebus apella (macaco-prego) que é mais resistente ao vírus. Estes ao se infectarem não morrem e desenvolvem anticorpos. Essa espécie pode estar relacionada à manutenção do ciclo silvestre da doença neste continente (WOLFE et al., 2001). 
A sensibilidade ao vírus da febre amarela, apresentada pelos macacos nas Américas, vem servindo como um importante indicador para surtos enzoóticos da doença em ambientes de mata (WOLFE et al., 2001).

Nos casos de febre amarela silvestre em humanos ocorridos no Brasil nos últimos anos, freqüentemente houve ocorrência de epizootia nos animais, anteriores à ocorrência dos casos humanos. As epizootias constituem um evento sentinela, para possível circulação do vírus da febre amarela silvestre entre a população de macacos.

No Brasil, epizootias vêm sendo registradas desde o ano de 2001, inicialmente no estado do Rio Grande do Sul.

Durante os anos de 2003 e 2004, outras epizootias ocorreram no país em vários estados, e em regiões fora de áreas delimitadas como endêmicas, como se pode observar nos anexos 1,2 e 3 .

O número de casos de febre amarela silvestre na população humana, a ocorrência de epizootias nos macacos e a circulação do vírus em regiões em que anteriormente não tinha sido registrada, motivou o Ministério da Saúde a fazer uma nova delimitação das áreas de ocorrência de febre amarela no Brasil, que passou de três áreas para 4 áreas epidemiológicas, inserindo uma Área de Risco Potencial para febre amarela, como demonstrado no anexo 4. 


\subsection{JUSTIFICATIVA}

A construção da Usina Hidroelétrica Engenheiro Sérgio Motta e o represamento do Rio Paraná deram origem ao Reservatório de Porto Primavera, uma das maiores represas brasileiras em volume armazenado e em área $\left(\mathrm{km}^{2}\right)$, atingindo os estados de São Paulo e Mato Grosso do Sul.

O Reservatório de Porto Primavera é localizado próximo ao município de Presidente Epitácio, município paulista da região Sudeste, que faz divisa com áreas endêmicas de febre amarela silvestre dos estados das regiões Centro-Oeste.

Devido às intensas comunicações rodoviárias, ferroviárias e aéreas entre essas regiões a circulação da população humana é intensa. Trata-se, na sua maioria, de pescadores, caminhoneiros e trabalhadores rurais que se deslocam várias vezes durante o ano para essas regiões à procura de trabalho.

Muitos desses trabalhadores mantêm contato com áreas florestais desses locais, onde também se registra a presença de animais silvestres, principalmente de macacos da espécie Alouatta caraya. Ao entrar nas matas o homem pode ser picado por mosquitos, pode infectar-se, fazendo com que na sua volta possa estar doente e disseminar a doença entre a comunidade.

O impacto ambiental provocado pelo desmatamento dessa grande área próxima ao município de Presidente Epitácio, levanta a preocupação do alto risco da doença entre a população humana que reside próxima a essas regiões impactadas ou que mantenham contato com as áreas de mata.

Durante estudos ecológicos sobre culicídeos no município de Bataguassu-MS foram encontradas larvas e adultos de Aedes albopictus, pela primeira vez em área 
enzoótica do vírus da febre amarela no Brasil. Este acontecimento pode sugerir risco potencial para transferência desse vírus para área urbana infestada com Ae. aegypti (GOMES et al., 1999).

O Ae. albopictus pode ser um vetor para febre amarela, pois se adapta facilmente aos ambientes modificados. Presume-se que o mosquito possa vir a servir de ponte entre os ciclos silvestre e urbano da doença, já que o mesmo demonstrou capacidade de transmitir dengue, febre amarela e vírus da encefalite eqüina venezuelana sob condições laboratoriais (MILLER et al., 1988).

Um outro aspecto diz respeito à emergência da doença nos estados da Bahia, Minas Gerais e São Paulo, e ainda às epizootias no Rio Grande do Sul, nas quais existem muitos aspectos desconhecidos, relacionados à dinâmica da circulação do vírus em ambientes com alterações relacionadas à interferência antrópica.

Esses recentes acontecimentos demonstram a importância de uma vigilância ativa sobre as populações de primatas não humanos. ¿̀ necessário detectar a circulação do vírus amarílico durante o período que ele ainda está restrito a uma epizootia, bem como determinar, pela presença de anticorpos, uma possível circulação de vírus, que pode reaparecer em outras localidades brasileiras exigindo, assim, desenvolvimento de pesquisas para fortalecer as medidas preventivas, controle da doença e principalmente intensificação vacinal. 


\section{OBJETIVOS}

\subsection{Objetivo Geral:}

Verificar a ocorrência de anticorpos contra o vírus amarílico em população simiana na região da Represa de Porto Primavera, Estado de São Paulo, Brasil.

\subsection{Objetivo Específico:}

Verificar a prevalência de anticorpos para o vírus da febre amarela em amostras de soros de macacos capturados em regiões distribuídas próximas às inundadas para formação do lago da Hidrelétrica de Porto Primavera.

Padronizar Teste Imunoenzimático (ELISA) para detecção de anticorpos da classe IgG em soros de macacos da espécie Alouatta caraya. 


\section{MATERIAIS E MÉTODOS}

\section{1 Área de Estudo}

A área de estudo situa-se à margem esquerda do lago formado pelo represamento do Rio Paraná, na região do Reservatório da Usina Hidrelétrica (UHE) Engenheira Sergio Mota, conhecida popularmente como UHE de Porto Primavera, localizada no Município de Presidente Epitácio, Região Oeste do Estado de São

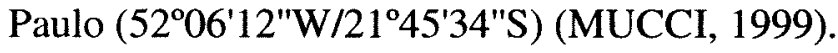

A área faz limite ao Norte pelo Rio do Peixe, ao Sul pelo Córrego do Veado, ao Leste pelo Córrego Água Sumida e ao Oeste pelo Rio Paraná. O reservatório está distante aproximadamente $100 \mathrm{~km}$ da barragem, que se localiza no Município de Porto Primavera (Figura 2) (MUCCI, 1999).

A vegetação da região anterior ao enchimento caracterizava-se como fragmento de Floresta Estacional Semidecidual (Fundação IBGE, 1998) e apresenta clima do tipo Aw-Tropical de inverno seco, segundo o sistema de classificação de Köeppen, atingindo temperaturas médias entre $19^{\circ}$ e $26^{\circ} \mathrm{C}$, nos meses frio e quente, respectivamente. A precipitação média anual oscila entre 1000 e $1400 \mathrm{~mm}$, com a média do mês mais seco não excedendo os $30 \mathrm{~mm}$ de chuva. (ALENCAR et al., 1976).

A área de interesse compreende as várzeas da margem esquerda do reservatório que, no passado, corresponderam à planície de inundação do Rio Paraná e apresentavam, em períodos anteriores ao represamento de água, extensas matas 
ciliares com uma grande diversidade de fauna, destacando-se as populações de macacos.

As populações humanas estabeleceram-se nos ambientes terrestres mais altos e adjacentes, fora da zona de influência fluvial direta. Estes ambientes compunham uma área de preservação que, em época anterior ao enchimento, era denominada Reserva Biológica da Lagoa São Paulo (52 $\left.05^{\prime} \mathrm{W} / 21^{\circ} 47^{\prime} \mathrm{S}\right)$. Iniciava-se ao Sul nas proximidades da cidade de Presidente Epitácio e ao Norte, expandindo-se além da desembocadura do Rio do Peixe, cuja via de acesso é a estrada asfaltada que liga a sede do Município ao Distrito Rural do Campinal (NATAL, 2001).

As inundações do reservatório, ocorridas em dois períodos: Janeiro de 1999 e Março de 2001, não atingiram diretamente esta área, entretanto, alguns pontos do Bairro do Campinal distam apenas alguns metros das novas margens que se formaram após o último enchimento (DUARTE, 2003).

O Reassentamento Lagoa São Paulo, vizinho do Bairro do Campinal, foi construído em 1980 sendo formado por 5 agrovilas, inicialmente com 516 famílias que habitavam as áreas de várzea da antiga Reserva Biológica da Lagoa São Paulo e Ilhas do Rio Paraná, áreas que atualmente se encontram submersas (DUARTE, 2003).

Entretanto, com o atraso na construção da represa e a conseqüente inundação, inúmeros posseiros e grupos de "sem-terra" invadiram, ao longo do tempo, as áreas desocupadas, e em função desta situação, a população da área, no momento, é bastante heterogênea no que se refere à procedência dos indivíduos e tempo de permanência dos mesmos na área (DUARTE, 2003). 


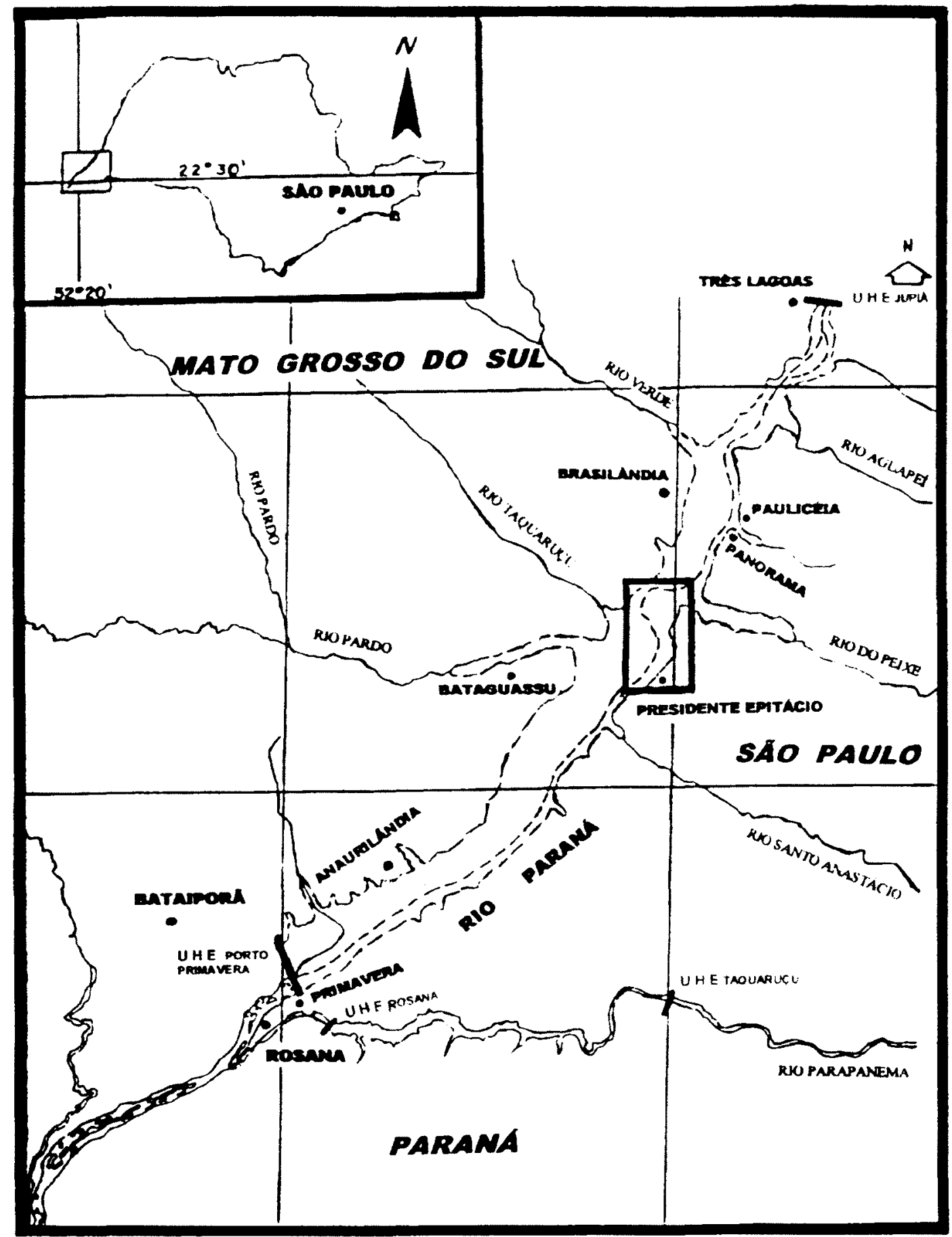

Figura 1 - Localização da UHE Porto Primavera e da área de estudo (retângulo), em relação ao Estado de São Paulo, sobre croqui cedido pela Companhia Energética de São Paulo (CESP).

Fonte: PAULA, 2001. 
Os macacos desse estudo foram capturados pela equipe técnica da Divisão de Resgate de Fauna da CESP (Companhia Energética de São Paulo), composta por veterinários, biólogos e técnicos de Meio Ambiente, com autorização do Instituto Brasileiro de Meio Ambiente (IBAMA), cuja cópia está no anexo 5.

As áreas envolvidas nesta atividade corresponderam às regiões alagadas das margens do Rio Paraná, adjacentes aos estados de São Paulo e Mato Grosso do Sul.

\section{2 Período do Estudo}

Os trabalhos de resgate dos animais ocorreram em dois períodos: Maio de 2000 e entre Março e Maio de 2001. Foram resgatados aproximadamente 2000 macacos, além de inúmeros exemplares de mamíferos, aves, répteis e anfíbios.

A grande maioria dos animais foi realocada em grandes fazendas e áreas de preservação no Estado do Mato Grosso do Sul.

Foram obtidas 570 amostras de material biológico de bugios (Alouatta caraya), sendo alguns espécimes capturados nas matas ciliares que existiam ao longo do Rio Paraná e Rio do Peixe, no território paulista, e outras em áreas próximas ao Bairro do Campinal e do Reassentamento Lagoa São Paulo. As amostras haviam sido testadas para malária em trabalho anterior (DUARTE, 2003). 


\section{3 Coleta de sangue de Macacos}

As amostras de sangue dos macacos foram coletadas, pela veia femural, em tubos tipo "Vacutainer" com anticoagulante (EDTA), em macacos previamente anestesiados com Ketamina, de acordo com a recomendação ética do Canadian Council On Animal Care (1980/1984).

As amostras de sangue foram separadas no Laboratório da Divisão de Meio Ambiente da CESP, em Presidente Epitácio, e conservadas em freezer $-20^{\circ} \mathrm{C} . \mathrm{O}$ material biológico obtido foi transportado em gelo seco até o Laboratório de Doenças Tropicais da Faculdade de Saúde Pública da Universidade de São Paulo, onde as amostras foram processadas.

Todos os procedimentos foram realizados por veterinários das equipes de resgate da CESP, empresa responsável pelo captura e relocação dos animais resgatados. 


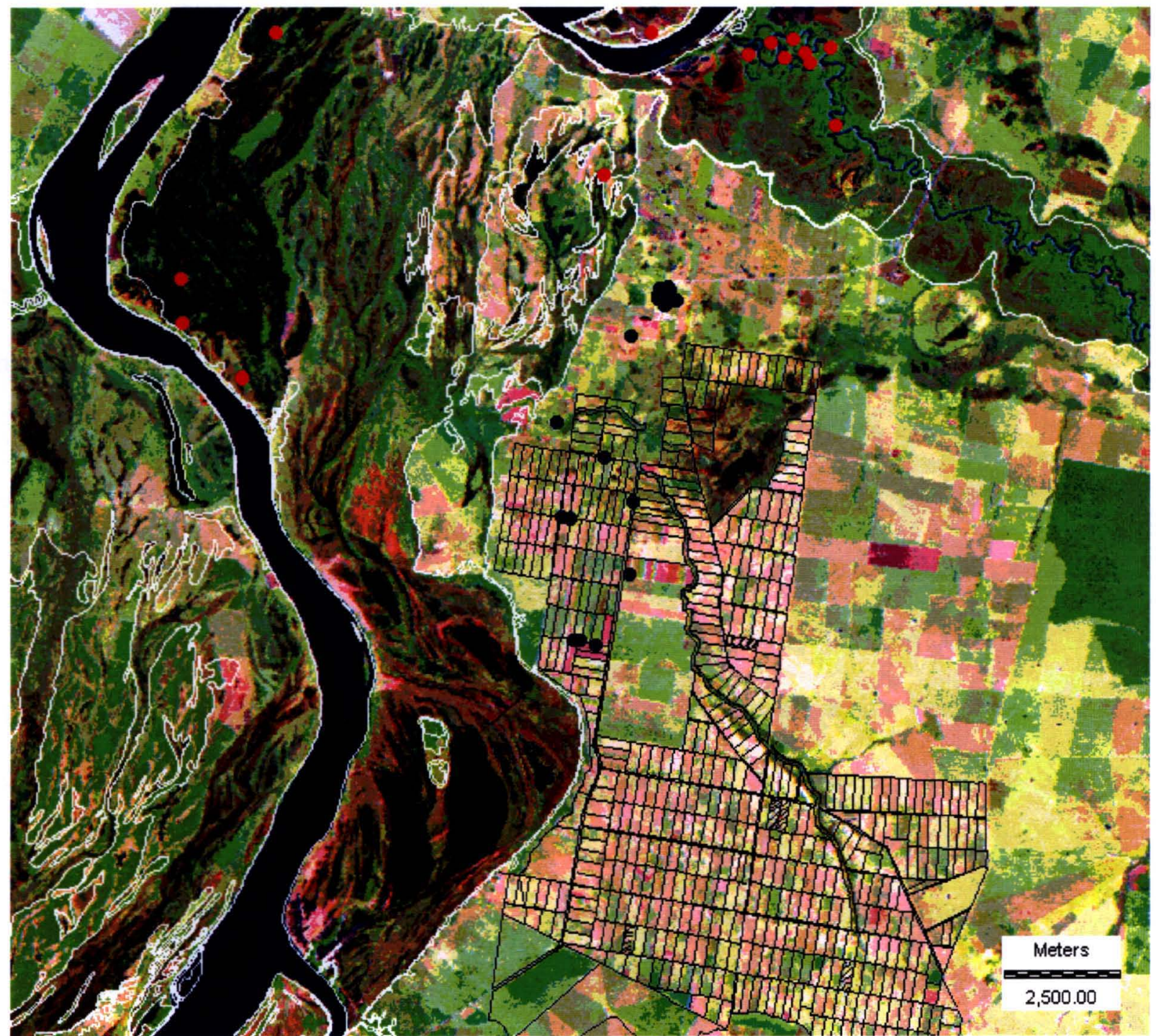

Figura 3 - Composição de Imagens LANDSAT TM345 de 09/03/97.

Área de Estudo: Município de Presidente Epitácio: Campinal e Reassentamento Lagoa São Paulo (RLSP).

Pontos Vermelhos: locais de captura dos bugios (Alouatta caraya).

Fonte: MUCCI, 1999. 


\section{4 Teste Imunoenzimático - ELISA}

O teste imunoenzimático, ELISA, é uma técnica sorológica que utiliza antígenos ou anticorpos adsorvidos a uma fase sólida insolúvel. A proteína adsorvida é usada para "capturar" o anticorpo que se pretende identificar na solução teste.

O complexo antígeno-anticorpo é detectado por um conjugado, um antígeno ou anticorpo ligado a uma enzima, que tem preservadas as suas atividades imunológica e enzimática.

Essa técnica foi desenvolvida por ENGVALL \& PERLMANN no início da década de 70 (ENGVALL et al., 1971; ENGVALL \& PERLMANN 1972; ENGVALL \& PERLMANN; 1971). Esses autores, além de AVRAMEAS \& GUILBERT (1971), empregaram a técnica para quantificar proteínas séricas, em especial IgG, observando que sua sensibilidade era próxima à do teste de radioimunoensaio, podendo ser aumentada de acordo com a pureza do antígeno empregado no teste.

A técnica foi empregada pela primeira vez em estudo de arbovírus por DITTMAR et al (1979) na pesquisa de anticorpos para o vírus da dengue e por FRANZIER \& SHOPE (1979) na identificação de anticorpos para vírus do gênero Alphavirus. Ambos os estudos foram publicados nos EUA, em 1979.

No Brasil, o uso do teste imunoenzimático em estudos de arbovírus foi introduzido em 1984 por IVERSSON et al para diagnóstico de infecções humanas pelo vírus Rocio (IVERSSON, 1985; IVERSSON, 1987) e, posteriormente, para diagnóstico de Febre Amarela e Dengue (COIMBRA et al. 1987; IVERSSON et al., 1986). 
Entre os métodos laboratoriais para pesquisa de anticorpos e antígenos virais em população humana, reservatórios e artrópodes vetores. O Teste Imunoenzimático, ELISA (Enzyme-Linked Immunosorbente Assay), tem se destacado como um método rápido e sensível, o desempenho do teste é comparado ao de técnicas tradicionalmente empregadas para pesquisa de arbovírus como os testes de Neutralização (N), Inibição de Hemaglutinação (IH), Imunofluorescência (IF) e Fixação de Complemento (FC) (ROMANO, 1990).

Atualmente, a técnica mais utilizada na vigilância epidemiológica de Dengue e Febre Amarela tem sido o Mac ELISA, que é um ensaio de captura de anticorpos da classe IgM no soro a ser pesquisado, através de uma anti-IgM humana ligada à placa do teste. Após as diversas etapas do ensaio, a presença do anticorpo é demonstrada pela mudança de cor no substrato ao sofrer ação enzimática do conjugado.

Os diagnósticos de infecções recentes pelos vírus Dengue, Febre Amarela e Rocio são realizados segundo o método descrito por KUNO et al. (1987) (TRAVASSOS DA ROSA et al., 1995). A técnica também tem sido usada em inquéritos sorológicos para flavivírus uma vez que é considerada rápida simples e confiável para diagnóstico sorológico de infecções primárias e secundárias para aqueles agentes (FIGUEIREDO e SHOPE, 1987). 


\subsection{Preparo dos Reagentes}

\subsubsection{Fluído Ascítico Imune de Febre Amarela.}

O Fluído ascítico imune utilizado, foi preparado no Laboratório de Virologia da Faculdade de Medicina da Universidade de São Paulo, no campus de Ribeirão Preto, segundo o protocolo de BRANDT et al (1967).

\subsubsection{Antígeno de Febre Amarela.}

$\mathrm{O}$ vírus amarílico foi inoculado pela via intracerebral em camundongos recém-nascidos. Os animais foram observados por 2 semanas quanto ao desenvolvimento de encefalite. Os animais inoculados adoecem entre o $4^{\circ}$ e o $6^{\circ}$ dia após a inoculação, desenvolvendo sinais de encefalite.

Os animais moribundos eram sacrificados e congelados em freezer a $-70^{\circ} \mathrm{C}$ Posteriormente, os cérebros dos animais eram coletados por aspiração. Após descongelamento, os mesmos foram misturados e triturados em gral e pistilo e diluídos $1 / 20(\mathrm{p} / \mathrm{v})$ em meio de cultivo celular RPMI, sendo armazenados a $-70^{\circ} \mathrm{C}$ como sementes virais.

Para determinação dos títulos do vírus $\left(\mathrm{LD}_{50}\right)$ contidos nas sementes virais estas ficaram diluídas em meio de cultivo celular RPMI de forma decimal a $10^{-4,} 10$ ${ }^{-5}, 10^{-6}, 10^{-7}, 10^{-8}$ e $10^{-9}$. Sementes virais de cada vírus e em cada uma destas diluições foram inoculadas em ninhadas de 6 camundongos recém-nascido ( 2 dias). Após 2 semanas da inoculação os animais mortos eram registrados e os títulos virais ( $\mathrm{LD}_{50}$ ) determinados pelo método de Reed-Muench (REED-MUENCH, 1983). 
O antígeno também foi preparado no Laboratório de Virologia da Faculdade de Medicina da Universidade de São Paulo, no campus de Ribeirão Preto.

\subsection{Padronização do Teste Imunoenzimático.}

\section{6.1 Padronizações da Reação de ELISA com soros humanos.}

Inicialmente, foram realizadas testes de padronização utilizando o protocolo do Centro de Controle de Doenças (CDC) de Atlanta, EUA, com algumas modificações, para testar soros humanos. Optou-se por este trabalho inicial porque foram observadas dificuldades para obtenção do soro controle positivo de macaco e, uma vez obtido este material, a alíquota não era suficiente para padronizar todos os reagentes utilizados no ensaio.

Os soros humanos utilizados no teste de padronização referiam-se a 8 amostras de soros positivos (vacinados nos últimos dez anos) e 4 amostras de soros negativos para febre amarela. Os soros foram coletados de funcionários e alunos do Laboratório de Doenças Tropicais da Faculdade de Saúde Pública - USP, os quais referiram não ter contraído dengue ou outra arbovirose.

O objetivo dos testes iniciais era conhecer as melhores diluições dos reagentes que poderiam ser utilizadas na triagem das amostras dos macacos.

Embora a densidade ótica verificada com diferentes titulações de fluido ascítico, soro e antígeno tivessem valores muito próximos, optou-se por utilizar as concentrações de 1:200 para o primeiro, 1:40 para os soros e 1: 320 para o antígeno. 
Após a determinação das concentrações consideradas ideais para o teste, foi testada uma amostra de soro humano positivo e uma de soro negativo. Os resultados destes testes estão expressos nas Tabelas 6, 7, 8, 9 em anexo.

As leituras das densidades óticas do teste mostram a diferença entre os oito soros positivos testados e os 4 soros negativos, indicando que as concentrações escolhidas eram adequadas. Os resultados desta reação estão expressos na Tabela 11, em anexo.

\subsubsection{Padronização da Reação de ELISA com soros de Macacos.}

Tomando por base a reação de ELISA padronizada com soros humanos, foram testados 19 soros de macacos para determinação de controle negativo.

As amostras utilizadas como controles negativo foram coletados de animais do Núcleo de Procriação de Macaco-Prego (Cebus apella) da Faculdade de Odontologia da UNESP, campos de Araçatuba (SP).

Esses animais vivem soltos em uma reserva florestal localizada dentro do Campus da Universidade. Após serem testados, os soros obtidos desses animais foram utilizados como controles negativos na padronização da reação.

O soro controle positivo utilizado neste trabalho foi fornecido pelo Laboratório de Flavivírus da Fundação Oswaldo Cruz (FIOCRUZ).

Para a padronização dos testes foram realizadas titulações em bloco para conhecer a melhor concentração do fluido ascítico, do antígeno e dos soros que seriam usados como controles negativos. 
Inicialmente, foi feita a titulação em bloco do fluido ascítico usando diluições crescentes partindo de 1:200, 1:400, 1:800 até 1:1600. Após a titulação do fluido ascítico, foi realizada a titulação em bloco dos soros e do antígeno começando por uma diluição crescente partindo de 1:40, 1:80, 1:160, 1:320 até 1:640.

Depois das titulações do fluido ascítico, antígeno e soros, foram realizados testes para se conhecer a melhor diluição do conjugado utilizado neste trabalho: conjugado anti-IgG de macaco Rhesus com peroxidase (Sigma- A-2054).

\subsubsection{Técnica final, utilizada após as padronizações:}

A descrição dos reagentes e materiais utilizados é apresentada no 12.

1 - Fase de Sensibilização: Microplacas de Poliestireno Maxisorp/NUNC com 96 cavidades foram previamente sensibilizadas com $100 \mu \mathrm{l}$ de solução para sensibilização, por cavidade. As placas foram incubadas a $4^{\circ} \mathrm{C}$ durante a noite.

2 - Fase Bloqueio: Terminado o período de sensibilização, as placas foram lavadas por cinco vezes. Em seguida foi realizado o bloqueio utilizando leite desnatado, dissolvido em PBS. Foram pipetados $250 \mu \mathrm{l}$ da solução de bloqueio, em cada cavidade. Foi realizada uma nova incubação por 1 hora em estufa a $37^{\circ} \mathrm{C}$. Nesta fase da reação não ocorreu o ciclo de lavagens.

3 - Antígeno: $O$ antígeno foi diluído na solução de bloqueio, foram dispensados $100 \mu l$ por cavidade. A placa foi novamente submetida a uma incubação por 1 hora em estufa a $37^{\circ} \mathrm{C}$. Terminado esse período, as placas foram lavadas com solução de lavagem PBS. 
4 - Diluição dos Soros: Os soros foram diluídos em 1:40 em solução de diluição e foram pipetados $100 \mu \mathrm{l}$ por cavidade. As placas foram novamente submetidas a uma incubação por 1 hora em estufa a $37^{\circ} \mathrm{C}$. Terminado esse período, as placas sofreram um novo ciclo de 5 lavagens.

5 - Conjugado: O conjugado de macaco Rhesus (Sigma A-2054) com peroxidase foi diluído na proporção de 1:300, em solução de leite desnatado (Molico, Nestlé a $2,5 \%$ ) e colocados $100 \mu 1$ por cavidade. As placas foram novamente submetidas a uma incubação por 1 hora em estufa a $37^{\circ} \mathrm{C}$. Após essa incubação, as placas foram novamente submetidas ao ciclo de 5 lavagens.

6 - Substratos ABTS (Peroxidase substrate e Peroxidase (H2O2) foram utilizados), $100 \mu 1$ do substrato por cavidade. As placas foram deixadas à temperatura ambiente e colocadas em recipiente sem presença de luz, para desenvolvimento de cor. Passado 15 minutos, foi realizada a leitura no aparelho Labsystems Multiskan (Finlândia) em comprimento de onda de $405 \mathrm{~nm}$.

\subsubsection{Estabelecimento do ponto de corte (cut-off).}

Após a padronização dos testes foram calculados os limiares de reatividade utilizando 19 amostras de soros de macacos confinados provenientes do zoológico de Araçatuba. Para uma maior especificidade dos resultados das reações de ELISA, o limiar de reatividade foi determinado acrescentando às médias aritméticas das absorbâncias dos soros negativos, 3 desvios-padrão, obtendo-se assim os resultados dos cálculos com os soros de macacos. 
Cut-off = Média das absorbâncias das amostras negativas +3 Desvio padrão (CURADO, 1995; CURADO, 2003; DUARTE, 1998; DUARTE, 2003; MARASSÀ, 2003).

As amostras com valores acima do "cut-off" foram consideradas positivas e as amostras com valores abaixo do mesmo, foram consideradas negativas para a presença de anticorpos para febre amarela.

Em todas as reações foram testados soros controle positivo, negativo e "blank". As amostras foram testadas em duplicata. Os resultados mais satisfatórios foram os que apresentaram maiores densidades ópticas para os soros controles positivos e menores densidades ópticas para os soros controles negativos. 


\section{RESULTADOS}

\subsection{Padronização da reação enzimática para pesquisa de anticorpos da classe IgG em soros de macacos}

A partir dos resultados com os soros humanos, positivos e negativos, foram determinadas as diluições para o teste com os soros de macacos. Considerou-se o soro como reativo quando ele apresentou leitura superior a três desvios padrão adicionados à média dos controles negativos, conforme FIGUEIREDO et al., (1987; 1989), que trabalharam com o teste imunoenzimático diretamente em cultura de células de Aedes albopictus.

Após as padronizações, optou-se por utilizar as seguintes diluições de reagentes: soros a 1:40, fluido ascítico a 1:400, antígeno a 1:320 e conjugado anti-macaco a $1: 3000$.

A Tabela 1 mostra os valores expressos em absorbância obtidos com soros negativos para a determinação do limiar de reatividade do ("cut-off"). A média das absorbâncias foi 0,060 e o Desvio Padrão (DP) foi de 0,030. Assim, o limiar de reatividade (média $+3 \mathrm{DP}$ ) foi de 0,150 . Os soros foram considerados positivos para a presença de anticorpos para febre amarela quando apresentaram valor de absorbância superior a este e negativos quando o valor foi inferior.

As Tabelas 2 e 3, que apresentam os resultados da titulação do antígeno e do fluido ascítico imune, mostram que as leituras das densidades óticas foram muito próximas para as diferentes diluições testadas. Assim, optou-se por utilizar as maiores diluições que expressassem a diferença entre amostras positivas e negativas 
e que fossem fáceis de manusear para facilitar o preparo das diluições, sem perda da exatidão no momento da pipetagem. Os resultados das padronizações dos soros controles positivos e negativos e da titulação do conjugado anti-macaco são apresentados a seguir nas Tabelas de 4 e 5 .

Tabela 1 - Valores expressos em absorbância $(405 \mathrm{~nm})$ para reação de ELISA utilizanpara cálculo do Limiar reatividade ("cut-off”). Reação com antígeno de febre amarela de soros de macacos de cativeiro $(\mathrm{N}=19)$ para cálculo do Limiar reatividade (“cut-off'). Diluição dos soros: 1:40, conjugado anti-IgG de macaco: 1:3000 (Sigma - A-2054). Substrato ABTS. Valores expressos em absorbância (405nm).

\begin{tabular}{c|c}
\hline Amostras Soros & Absorbâncias \\
\hline 01 & 0,080 \\
02 & 0,039 \\
03 & 0,059 \\
04 & 0,105 \\
05 & 0,058 \\
06 & 0,047 \\
07 & 0,028 \\
08 & 0,105 \\
09 & 0,055 \\
10 & 0,057 \\
11 & 0,029 \\
12 & 0,076 \\
13 & 0,082 \\
14 & 0,043 \\
15 & 0,004 \\
16 & 0,131 \\
17 & 0,035 \\
18 & 0,057 \\
19 & 0,048 \\
\hline Média & $\mathbf{0 , 0 6 0}$ \\
\hline
\end{tabular}


Tabela 2 - Padronização da diluição de fluido ascítico anti-febre amarela utilizando soro controle positivo de macaco na diluição de 1:40.

\begin{tabular}{c|c|c|c|c|c|c}
\hline & \multicolumn{7}{|c}{ Antígeno } \\
Fluido Ascítico & \multicolumn{7}{|c}{ Diluição } & $1: 20$ & $1: 40$ & $1: 80$ & $1: 160$ & $1: 320$ & $1: 640$ \\
\cline { 2 - 7 } & 1,533 & 1,444 & 1,344 & 1,313 & 1,108 & 0,964 \\
\hline $1: 200$ & 1,002 & 0,987 & 0,886 & 0,765 & 0,605 & 0,505 \\
\hline $1: 400$ & 0,601 & 0,503 & 0,440 & 0,313 & 0,277 & 0,231 \\
\hline $1: 800$ & 0,235 & 0,189 & 0,156 & 0,127 & 0,099 & 0,075 \\
\hline
\end{tabular}

Conjugado Anti- Monkey (IgG) Sigma A:2054 com peroxidase, utilizado na concentração de 1:3000. Substrato: ABTS. Leitura das Densidades óticas em $405 \mathrm{~nm}$. Aparelho Multiscan

Tabela 3 - Padronização da diluição de fluido ascítico imune anti-febre amarela utilizando soro controle negativo de macaco na diluição de 1:40.

\begin{tabular}{c|c|c|c|c|c|c}
\hline & \multicolumn{5}{|c}{ Antígeno } \\
\hline & \multicolumn{7}{|c|}{ Diluição } & \multicolumn{7}{|c}{} \\
\cline { 2 - 7 } & $1: 20$ & $1: 40$ & $1: 80$ & $1: 160$ & $1: 320$ & $1: 640$ \\
\hline $1: 200$ & 0,083 & 0,080 & 0,071 & 0,049 & 0,035 & 0,016 \\
\hline $1: 400$ & 0,071 & 0,054 & 0,052 & 0,044 & 0,039 & 0,010 \\
\hline $1: 800$ & 0,052 & 0,046 & 0,040 & 0,016 & 0,022 & 0,005 \\
\hline $1: 1640$ & 0,037 & 0,035 & 0,022 & 0,008 & 0,002 & 0,001 \\
\hline
\end{tabular}

Conjugado Anti- Monkey (IgG) Sigma A:2054 com peroxidase, utilizado na concentração de 1:3000. Substrato: ABTS. Leitura das Densidades óticas em $405 \mathrm{~nm}$. Aparelho Multiscan 
Tabela 4 - Titulação de Conjugado Anti- Monkey (IgG) com soro de macaco positivo.

\begin{tabular}{c|c|c|c}
\hline \multicolumn{1}{|c|}{ Diluição } & \multicolumn{3}{|c}{ Conjugado } \\
Soros & $(1: 1000)$ & $(1: 2000)$ & $(1: 3000)$ \\
\hline $1: 20$ & 2,662 & 1,444 & 1,254 \\
\hline $1: 40$ & 1,298 & 1,210 & 0,987 \\
\hline $1: 80$ & 1,185 & 1,139 & 0,803 \\
\hline $1: 160$ & 1,177 & 1,106 & 0,589 \\
\hline $1: 320$ & 1,150 & 1,005 & 0,497 \\
\hline $1: 640$ & 1,028 & 0,934 & 0,391 \\
\hline
\end{tabular}

Conjugado Anti- Monkey (IgG) Sigma A:2054 com peroxidase 1:3000; fluido ascítico: 1:200; antígeno 1:320. Substrato: ABTS. Leitura das Densidades óticas em $405 \mathrm{~nm}$. Aparelho Multiscan

Tabela 5 - Titulação de Conjugado Anti- Monkey (IgG) com soro de macaco negativo.

\begin{tabular}{c|c|c|c}
\hline \multicolumn{1}{|c|}{ Diluição } & \multicolumn{3}{|c}{ Conjugado } \\
Soros & $(1: 1000)$ & $(1: 2000)$ & $(1: 3000)$ \\
\hline $1: 20$ & 0,087 & 0,070 & 0,055 \\
\hline $1: 40$ & 0,078 & 0,062 & 0,043 \\
\hline $1: 80$ & 0,064 & 0,050 & 0,037 \\
\hline $1: 160$ & 0,051 & 0,045 & 0,028 \\
\hline $1: 320$ & 0,039 & 0,031 & 0,019 \\
\hline $1: 640$ & 0,023 & 0,014 & 0,001 \\
\hline
\end{tabular}

Conjugado Anti- Monkey (IgG) Sigma A:2054 com peroxidase 1:3000; fluido ascítico: 1:200; antígeno 1:320. Substrato: ABTS. Leitura das Densidades óticas em $405 \mathrm{~nm}$. Aparelho Multiscan 


\subsection{Pesquisa de anticorpos para febre amarela em soros de macacos.}

Não foram encontrados anticorpos da classe IgG para febre amarela em nenhum dos 570 soros de macacos que foram testados com reação sorológica imunoenzimática de ELISA.

Os resultados do teste ELISA estão expressos em tabela apresentada no anexo 13. 


\section{DISCUSSÃO}

\subsection{Sobre a padronização da reação imunoenzimática (ELISA).}

A técnica imunoenzimática (ELISA), é um instrumento adequado para emprego na vigilância epidemiológica de arboviroses, especialmente para identificação de anticorpos em humanos e não humanos e na pesquisa de fonte alimentar de mosquito vetores (MARASSÁ, 2003).

A padronização da técnica para pesquisa de anticorpos do tipo IgG para febre amarela, realizada neste trabalho, tanto em soros humanos como em soros não humanos, mostrou-se eficaz para diferenciar soros positivos e soros negativos. Tradicionalmente, a técnica tem sido utilizada para estudar a circulação de anticorpos do tipo IgM para arbovírus (VASCONCELOS, 2002, VASCONCELOS 2003).

A sorologia é importante no diagnostico das infecções por Flavivírus e na diferenciação entre infecções primárias e secundárias. De maneira geral, a Inibição de Hemaglutinação (IH) tem sido usada para classificar as respostas imunológicas em primárias (aumento gradual de anticorpos a um título moderado) ou secundárias (aumento rápido a títulos elevados), visto que detecta imunoglobulinas totais, principalmente IgG (que perduram por um longo período de tempo), constituindo um teste útil para estudos soroepidemiológicos.

Por outro lado, o teste de ELISA-IgM (Mac-ELISA) é muito importante no diagnostico rápido das infecções correntes e ou recorrentes, pois IgM surge na primeira semana após o inicio dos sintomas, alcança um pico na segunda semana e 
perdura por 2 a 3 meses (MANCINI et al.,1965; WHO, 1986, 1988 a,b, 1999, 2001; ARAÚJO, et al., 2002, VASCONCELOS, 2002, 2003).

No Brasil, os laboratórios oficiais utilizam os testes de IH e o MaC-ELISA para diagnostico sorológico da dengue e da febre amarela (WHO, 1998; VASCONCELOS, 2002, 2003). O teste IH, apesar de ser uma das provas indicadas para o diagnóstico destes agravos pela Organização Mundial de Saúde, apresenta problemas que foram observados no trabalho de FELIPPE (2005). Neste, a extração pela acetona (necessária para a retirada de outros hemaglutinantes do soro) estaria desnaturando de forma definitiva uma grande quantidade de anticorpos passíveis de serem detectados em outros testes imunológicos como a ELISA.

A prova de Fixação de Complemento, por sua vez, também tem sido pouco utilizada devido à necessidade de um pessoal treinado (quando se considera a sua utilização fora de laboratórios de referência) para sua execução e também pelo alto índice de reações cruzadas observadas, que muitas vezes são iguais ou até mesmo maiores do que as para o flavivírus realmente infectante (FELIPPE, 2005).

Devido às dificuldades encontradas pode-se observar na literatura um esforço no sentido de buscar um método rápido, eficaz e suficiente para detectar a infecção primária através da revelação de IgM reativa aos antígenos virais. Assim, existe hoje no mercado uma grande quantidade de testes comerciais direcionados a detecção de antígenos virais de Flavivírus destinados a soros humanos e baseados no ELISA (WHO, 1998 a, b; GROEN et al., 2000; SATISH, 2003).

Os resultados obtidos neste trabalho mostram que a técnica de ELISA adaptada para pesquisa de anticorpos do tipo IgG em animais silvestres, apresentou essas características de rapidez e eficácia. Ainda, o teste em macacos pôde ser 
realizado utilizando conjugado comercial anti-macacos, independente da espécie testada facilitando o trabalho de investigação. Outra vantagem é que a técnica possibilita o processamento e a análise de um grande número de amostras, o que representa aspecto importante numa investigação epidemiológica. Desta forma, a técnica de ELISA adaptada para estudos de identificação de anticorpos IgG pode ser utilizada como mais uma opção para a vigilância epidemiológica de febre amarela em animais reservatório, por laboratórios de referência ou centros de primatas.

\subsection{Sobre a pesquisa de anticorpos para febre amarela em soros de macacos}

Todos os soros testados não foram reativos para a presença de anticorpos contra o vírus da febre amarela. Os resultados do teste sorológico são coerentes com a epidemiologia da febre amarela silvestre na região. Mesmo sendo considerada área

de transição para febre amarela pelo Ministério da Saúde, não se conhece, até o momento, ocorrência de epizootia ou surto de febre amarela na população humana na área.

Investigações entomológicas realizadas naquela região também não têm apontado a presença de vetores de febre amarela. Assim, levantamento da fauna de culicídeos na região de Presidente Epitácio, área próxima à UHE de Porto Primavera, realizado por PAULA (2001) não encontrou a presença de mosquitos dos gêneros Sabethes e Haemagogus.

Da mesma forma, CAMARGO-NEVES et al. (2005) realizaram investigações entomológicas com o objetivo de verificar a ocorrência das espécies vetoras nas regiões Oeste e Noroeste do Estado de São Paulo. Foram realizadas 
coletas em 39 localidades distribuídas por quatro regiões do Estado. As espécies mais abundantes foram Haemagogus leucocelaenus e Ae. albopictus. Hg.leucocelaenus foi a espécie mais abundante nos Municípios de Santa Albertina e Ouroeste, onde ocorreram casos de febre amarela silvestre no ano de 2000. Na região de Presidente Epitácio, área na qual foram capturados os macacos objeto deste trabalho foi relatado o encontro de 16 mosquitos do gênero Sabethes. Entretanto, não foram encontrados mosquitos do gênero Haemagogus ou Ae. albopictus.

Primatas não-humanos podem servir, em certos casos, como animaissentinela de determinados ciclos zoonóticos silvestres. Estes ciclos podem ser detectados quando constatada a ocorrência de epizootias, tais como as causadas por arbovírus e, particularmente, pela febre amarela.

Animais do gênero Allouata, como os avaliados neste estudo, embora extremamente suscetíveis ao vírus da febre amarela, têm sido investigados com vistas à vigilância de febre amarela (ABRAVAS, 2005).

Assim, VALLE et al. (2002) realizaram um trabalho de sorologia, utilizando as técnicas de Inibição de Hemaglutinação (IH) e Teste de Neutralização (N) para 19 arbovírus, com 2 animais da espécie Alouatta caraya com o objetivo de pesquisar a presença de anticorpos para arbovírus. Os animais foram encontrados no município de Porto Rico (PR) cidade em que ocorreram casos de epizootia em fevereiro de 2001, e com último registro de FAS em 1966. Como resultado da pesquisa, foi encontrado anticorpos contra o vírus Oropouche. Pela primeira vez, demonstraram-se anticorpos para o vírus Oropouche em macacos de vida livre procedentes do Sul do Brasil. 
SALLIS et al. (2003), após epizootia ocorrida no Rio Grande do Sul, em 2001, realizaram necropsia e exame de imuno-histoquímica, em um animal da espécie Alouatta ifusca encontrado morto em Santo Antonio das Missões. A necropsia foi realizada no Laboratório de Patologia Veterinária do Hospital Veterinário da Universidade de Santa Maria e o exame de imuno-histoquímica no Instituto Evandro Chagas em Belém (PA). Foi detectada a presença de vírus de febre amarela, confirmando o diagnóstico da morte do animal por aquele agente.

Este fato determinou a reavaliação da situação do Rio Grande do Sul em relação à febre amarela. A região noroeste do estado passou de área indene para área de transição e foi instituída vacinação de toda a população dos municípios próximos e na população que viaja para a região (ABRAVAS, 2005).

Outras espécies de macacos têm sido pesquisadas com vistas à vigilância epidemiológica de febre amarela no Brasil. MALANSKI et al. (2002) utilizaram a técnica de Inibição de Hemaglutinação (IH) para avaliar e quantificar a presença de anticorpos específicos para 19 arbovírus em amostras de 101 macacos do gênero Cebus da colônia do Centro Nacional de Primatas de Ananindeua (PA). Foram encontrados anticorpos contra o vírus da encefalite de São Luís em apenas um animal. Nas demais amostras não foram detectados anticorpos para nenhum dos arbovírus pesquisados.

Em outubro de 2004, foi realizada uma investigação de epizootias em sagüis do Parque das Dunas, no Rio Grande do Norte, envolvendo varias instituições de pesquisa. Relata-se que, no período de fevereiro a agosto de 2004 , foram registrados cerca de 50 animais doentes e mortos, dos quais foram coletadas amostras de soro, 
sangue e tecidos para sorologia e isolamento viral. Em 11 amostras, não foram encontrados anticorpos para arbovírus.

Devido à sensibilidade de macacos da espécie Alouatta caraya ao vírus da febre amarela eles são bons indicadores da circulação viral. Entretanto, essa característica não serve como alerta para a tomada de medidas de prevenção, como vacinação. Assim, para a efetiva vigilância da febre amarela silvestre é adequado que haja a combinação da vigilância nos reservatórios aliada à vigilância entomológica das espécies vetores para aquela arbovirose. 


\section{CONCLUSÕES}

De acordo com os objetivos propostos, é possível concluir que:

1. A reação imunoenzimática para pesquisa de anticorpos anti IgG para febre amarela, em soros de macacos, mostrou-se rápida, capaz de ser realizada com conjugado comercial anti-macacos e, portanto, com utilidade para a vigilância epidemiológica da doença.

2. Não foram encontrados anticorpos da classe IgG para febre amarela em soros de macacos capturados na região da Usina Hidrelétrica de Porto Primavera.

3. A vigilância epidemiológica da febre amarela silvestre depende, além da observação da circulação viral nos reservatórios, de vigilância entomológica para que seja possível desencadear medidas de prevenção antes mesmo do surgimento de epizootias. 


\title{
Referências Bibliográficas
}

\begin{abstract}
ABRAVAS - Associação Brasileira de Veterinários de Animais Selvagens. http://www.abravas.com.br/04Captura\%20de\%20primatas\%20para\%20\%20\%20\%2 0\%20\%20detec\%E7\%E30\%20de\%20Febre\%20Amarela.pdf (consultado em 20/06/2006).
\end{abstract}

Alencar FMA, Nogueira JCB, Emmerich W. A lagoa São Paulo e alguns aspectos de sua fisiografia. São Paulo. Instituto Florestal. Boletim Técnico No 20; 1976.

Anderson CR, Downs WG. The isolation of yellow fever virus from the liver of naturally infected red howler monkeys. Am. J. Trop. Med. Hyg.1955. 4: 662-64.

Araújo TP. Rodrigues SG. Costa MLW. Vasconcelos PFC, Rosa APAT. Diagnostico sorológico de infecções por dengue e febre amarela em casos suspeitos no Estado do Pará, Brasil, 1999. Rev Soc. Bras Méd. Trop. 6: 35. Nov/Dec 2002.

Auricchio P. Primatas do Brasil. Terra Brasilis, São Paulo.

Avrameas S, Guilbert B. Dosage enzymo-immunologique de protéines à l'aide d'immunoadsorbants et d'antigènes marqués aux enzymes. C.R. Acad. Sci. 1971.273 (25): 2705-07. 
Benchimol JL. Febre Amarela: a doença e a vacina, uma história inacabada. (Coord). Rio de Janeiro. Ed. Fiocruz. 2001.

Bensabath G. Recuperacion de vírus amarílico procedente de um mono centinela em las cercanias de Belém, Brasil. Bol. OPAS. 1966. 60: 187-92.

Bonvicino CR. 1989. Ecologia e comportamento de Alouatta belzebul (Primates:Cebidae) na Mata Atlântica. Rev Nordestina Biol. 6(2): 149 - 179.

Boletim Eletrônico Epidemiológico - Secretaria de Vigilância em Saúde. Situação Atual da Febre Amarela no Brasil. Ano: $01 \mathrm{~N}^{\circ} 02 ; 2001$. http:// www. Funasa.gov.br (consultado em 11/03/2005).

Boletim Eletrônico Epidemiológico - Secretaria de Vigilância em Saúde. Epidemia de febre amarela silvestre na região da Bacia do Rio Doce-Minas Gerais. Dezembro de 2002 a Março de 2003. Ano: 03, No. 06; 2003. http:// www. Saúde.gov.br (consultado em 08/03/2006).

Boletim Eletrônico Epidemiológico - Secretaria de Vigilância em Saúde. Investigação de óbitos humanos de causa desconhecida ocorrida no Rio Grande do Norte e de epizootia em sagüis (Callithrix jaccus) no Parque das Dunas, Rio Grande do Norte, 2004. Ano: 04, N. 07; 2004. http:// www. Saúde.gov.br (consultado em 08/08/2005). 
Brandt WE, Buescher EL, Hetrick FM. Production and characterization of arbovirus antibody im mouse ascitic fluid. The American Jour. of Trop. Med. and Hyg. 1967. 16(3): 339-47.

Brés PLJ. A century of progress in combating yellow fever. Bulletin of the World Health Organization.1986. 64: $775-86$.

Canadian Council on Animal Care. Guide to the care and use of experimental animals. Ottawa. 1980-1984.

Camargo-Neves VLF, Poletto DW, Rodas LAC, Pachioli ML, Cardoso RP, Scandar SAS, Sampaio SMP, Koyanagui PH, Botti MV, Mucci LF, Gomes AC. Entomoligal investigation of a sylvatic yellow fever area in São Paulo State, Brazil. Cadernos de Saúde Pública. Rio de Janeiro. 2005. 21(4): 1278-86.

CESP - Companhia Energética de São Paulo. Estudo de Impacto Ambiental UHE de Porto Primavera. São Paulo. (Consorcio Themag - Engea- UMAH);1993.

CIVES - Centro de Informação em Saúde para Viajantes - UFRJ http:// www.cives.ufrj.br/informacao/fam/fam-br.html. (consultado em 18/05/2006).

Coimbra TLM, Iversson LB, Spir M, Alves VAF, Boulos M. Investigação Epidemiológica de casos de febre amarela na região noroeste do Estado de São Paulo, Brasil. Rev Saúde Pública. 1987. 21 (3) 193-99. 
Curado I. Soroepidemiologia de malária em áreas de baixa endemicidade no Estado de São Paulo [Dissertação de Mestrado]. São Paulo: Instituto de Ciências Biomédicas da USP; 1995.

Curado I. Estudo epidemiológico sobre a malaria humana e simiana e infecção de anofelinos em áreas de baixa endemicidade no Estado de São Paulo [Tese de Doutorado]. São Paulo: Faculdade de Saúde Pública da USP; 2003.

CVE - Centro de Vigilância Epidemiológica - Secretaria de Estado da Saúde de São Paulo. http:// www.cve.saude.sp.gov.br/htm/zoo/fa.informe.htm. (consultado em 10/01/06).

Davis NC, Shannon RC. Studies on South American yellow Fever. III. Transmision of the virus to brazilian monkeys. Preliminary observation. J.Exp. Med. 1929. 50 (1): $81-85$

Davis NC. Susceptibility of Capuchin (Cebus) monkeys to yellow fever virus. Am. J. Hyg. 1930. 11 (2): $321-34$.

Dittmar D. Immunoglobulin G - and M-especific enzyme-linked immunosorbent assay for detection of dengue antibodies. J.Clin.Microbiol. 1979. (4): 498-02. 
Duarte AMRC. Estudo de malária em macacos silvestres brasileiros [Dissertação de Mestrado]. São Paulo: Instituto de Ciências Biomédicas da USP; 1998.

Duarte. AMRC. Aspectos epidemiológicos da malária humana e simiana em área de influência do reservatório da usina hidrelétrica de Porto Primavera, município de Presidente Epitácio, São Paulo, Brasil [Tese de Doutorado] São Paulo: Faculdade de Saúde Pública da USP; 2003.

Engvall E. Enzyme-linked immunosorbent assay II. Quantitative assay of protein antigen, immunoglobulin G, by means of enzyme-labelled antigen and antibodycoated tubes. Biochim. Biophys. Acta. 1971. 251: 427-34.

Engvall E. Perlmann P. Enzyme-linked immunosorbent assay, ELISA III.

Quantitation of specific antibodies by enzyme labeled anti -immunoglobulin in antigen coated tubes. J. Immunol 1972. 109 (1): 129-35.

Engvall E. Perlmann P. Enzyme-linked immunosorbent assay, ELISA. Quantitative assay of immunoglobulin G. Immunochemistry. 1971.8 (9): 871-74.

Fé NF, Barbosa MGV, Fé FAA, Guerra MVF, Alecrim WD. Fauna de Culicidae em municípios da zona rural do Estado do Amazonas, com incidência de febre amarela. Ver. da Soc. Brasileira de Méd.Trop. 2003. 36 (3): 343 - 48. 
Felippe PAN. Pesquisa de anticorpos reativos com antígenos virais de dengue e da febre amarela em sangue de símios de áreas urbanas. [Dissertação de Mestrado] Instituto de Biologia . Universidade Estadual de Campinas. 2005

Figueiredo LTM, Shope RE. Na enzyme immunoassay for dengue antibody using infected cultured mosquito cells as antigen. J.Virol. Methods. 1987. 17:191-98.

Figueiredo LTM, Simões MC. Cavalcante SMB. Enzime immunoassay for the detection of dengue IgG and IgM antibodies using infected mosquito cells as antigen. Transactions of the Royal Society of Tropical Medicine and Hygyene, 83, 702-707. 1989

Frazier CL, Shope RE. Detection of antibodies to alphaviruses by enzyme-linked immunosorbent assay. J.Clin.Microbiol. 1979. 10 (4): 583-85.

Gomes AC, Bitencourt MD, Natal D, Pinto PLS, Mucci LF, Paula MB, Urbinatti PR, Barata JMS. Aedes albopictus em área rural do Brasil e implicações na transmissão de febre amarela silvestre. Rev Saúde Pública.1999. 33 (1): 95-97.

Groen J, Koraka P, Velzing J, Copra C, Osterhaus, ADME. Evaluation of six Immunoassays for Detection Of Dengue Vírus-Specific Immunoglobulin $M$ and $G$ Antibodies. Clinical and Diagnostic Laboratory Immunology, vol. 7, N $\mathrm{N}^{\circ}$, p. 867$871,2000$. 
Hirsch A., Landau, EC. Tedeschi ACM. Menegheti JO. Estudo comparativo das espécies do gênero Alouatta Lacépède, 1799 (Platyrrhini, Atelidae) e sua distribuição geográfica na América do Sul. In: Primatologia no Brasil. Fundação Biodiversitas, Sociedade Brasileira de Primatologia, Belo Horizonte. 1991

IBGE. Anuário Estatístico do Brasil: 1997. Rio de Janeiro, Volume: V; 1998.

Iversson LB. et al Teste imunoenzimático no diagnostico de arboviroses. Detecção de anticorpos IgM específicos antiflavivírus Rocio em infecções agudas. In: Congresso da Sociedade Brasileira de Medicina Tropical. 21․ São Paulo. 1985. Resumos Sociedade Brasileira de Medicina Tropical. P.170; 1985

Iversson LB. et al Utilização do teste imunoenzimático (ELISA) no diagnóstico de dengue e febre amarela no Estado de São Paulo em 1985. In: Congresso Brasileiro de Saúde Coletiva. 1986. Rio de Janeiro.

Iversson LB. Et al Use of immunoglobulin $\mathrm{M}$ antibody capture enzyme linked immunosorbent assay in the surveillance of Rocio encephalitis. In: Annual Meeting of the American Society Of Tropical Medicine And Hygiene. $36^{\circ}$. Los Angeles. 1987. Abstracts. American Society of Tropical Medicine and Hygyene. 1987. p.93.

Kinzey WG. Alouatta. In: New World Primates: Ecology, Evolution and Behavior, pp. 174-185. Aldine de gruyter, New York. 1997. 
Kuno G. et al. Detecting artificial anti dengue IgM immune complexes using an enzyme linked immunosorbent assay. Am.J.Trop. Med.Hyg. 1987. 36 (1):153-59.

Laemmert HW, Ferreira LC. Isolation of yellow fever vírus from wild-caught marmosets. Am. J. Trop. Med. 1945. 25:321-32.

Laemmert HW. An epidemiological study of jungle yellow fever in endemic área Brazil. Part II - Investigations of vertebrate hosts and arthropod vectors. Am. J. Trop. Med.1946. (suppl) 26 (6) : 23-69.

Laemmert HW, Kumm HW. The susceptibility of howler monkeys to yellow fever virus. Am. J. Trop. Med. 1950. 30 (5): 723-31.

Malanski LS. et al Levantamento sorológico de arbovírus em animais da espécie Cebus apella Cebuss nigrivittatus mantidos em cativeiro no Centro Nacional de Primatas . XXXIX CONGRESSO DA SOCIEDADE DE MEDICINA TROPICAL (resumos) Volume 36 (suppl. I) Belém, 16 a 21 de Março de 2003.

Mancini G, Carbonara AO, Heremans JF. Immunochemical Quantitation of Antigens by Single Radial Immunodiffusion Immunochemistry. 2:235. 1965.

Marassá, AM. Padronização da técnica imunoenzimática (ELISA) de captura para o estudo do habito alimentar de dípteros da subfamília Phebotominae [Dissertação de Mestrado] São Paulo: Faculdade de Saúde Pública da USP; 203. 
Mendez AS. Alas amarillas: La historia de Carlos J. Finlay y su descubrimento. Havana (Cuba): Editorial Cientifico - Técnica; 1983.

Ministério da Saúde. Secretaria de Vigilância em Saúde. Departamento de Vigilância Epidemiológica. Manual de Vigilância de Epizootias em Primatas Não-Humanos; 2004.

Ministério da Saúde. Secretaria de Vigilância em Saúde. Departamento de Vigilância Epidemiológica. Manual de Vigilância Epidemiológica de Febre Amarela; 1999.

Ministério da Saúde. Secretaria de Vigilância em Saúde. Departamento de Vigilância Epidemiológica. Manual de Vigilância Epidemiológica de Febre Amarela; 2004

Ministério da Saúde. Secretaria de Vigilância em Saúde. Departamento de Vigilância Epidemiológica. .http://drt2001.saúde.gov.br/svs/destaques/epizootias 1410.htm. (consultado em 10/01/2006).

Ministério da Saúde. Secretaria de Vigilância em Saúde. Departamento de Vigilância Epidemiológica. Coordenação Geral de Doenças Transmissíveis. Nota Técnica No 07/2006. Situação Epidemiológica da febre amarela no Brasil em 2006. http://www.portal.saúde.gov.br/portal/saude/visualizar texto.cfm?idtxt=21692 (consultado em 23/05/2006). 
Monath TP. Yellow fever: a medically neglected infectious disease. Reviews of Infectious Diseases. 1987. 9:165-75.

Monath TP. Yellow fever: In:Monath (ed) Arboviruses: ecology and epidemiology, volume V. CRC Press, Boca Raton, Florida. 1988. 39-241.

Monath TP. Yellow fever: An update. Lancet infectious Diseases. 2001. 11- 20.

Mucci LF. Modelagem espacial do risco epidemiológico para malária em porção paulista da zona de influência do Reservatório de Porto Primavera [Dissertação de Mestrado] São Paulo: Instituto de Biociências da USP; 1999.

Natal D. Efeitos da inundação sobre culicídeos, com ênfase na população de Aedes scapularis (Rondani, 1848), da área de influência Hidrelétrica de Porto Primavera [Dissertação de Livre Docência] São Paulo: Faculdade de Saúde Pública da USP; 2001.

Neville MK. Glander KE. Braza F. Rylands AB. The howling monkeys, genus Alouatta Ecology and Behavior of Neotropical Primates, Vol: 2, pp. 349-453. World Wildlife Fund, Washington, DC.1988.

Paula MB. Fauna de culicídeos (Díptera: Culicidae) em área sob influência do Lago Porto Primavera, Município de Presidente Epitácio, São Paulo, Brasil [Dissertação de Mestrado] São Paulo: Faculdade de Saúde Pública da USP; 1999. 
Rylands AB. Schneider H, Langguth A, Groves CP, Rodriguez-Luna E. Na Assessment of the diversity of New World Primates Neotropical. Primates8(2) 6193.

Romano. NS. O uso do teste imunoenzimático na vigilância epidemiológica de arboviroses. [Dissertação de Mestrado] São Paulo: Faculdade de Saúde Pública da USP; 1990.

Sallis ESV, Garmatz SL, Fighera RA, Barros VLR, Graça DL. Surto de febre amarela em bugios. Acta Scientiae Veterinariae. 2003. 31 (2): 115-17.

Santamaría-Gomez M. Ecologia e comportamento de Alouatta seniculus em uma mata de terra firme na Amazônia central [Dissertação de Mestrado] Universidade Federal de Minas Gerais (UFMG), Belo Horizonte. 1999.

Sathish N, Wjayakumar TS, Abraham P, Sridhararf G. Dengue Feber: It's Laboratory Diagnosis, with Special Emphasis on IgM Detection. Dengue Bulletin. Vol: 27. 2003

Soper FL. Jungle yellow fever: new epidemiological entity in South América. Revista de Hygiene e Saúde Pública. 1936. 10:107-44.

Soper FL. Febre amarela. O Hospital. 1942. 22: $141-71$.

Stroder GK. Yellow Fever: McGraw-Hill (ed), 1951. New York. 
SUCEN - Superintendência de Controle de Endemias. Avaliação do Programa de Controle de Malária. Estado de São Paulo - período de 1992 a 1994. 1995. São Paulo.

SUCEN - Superintendência de Controle de Endemias. Casos autóctones de malária, por ano e local provável de infecção, região do Planalto Ocidental, 1990 a 2000. http://www.sucen.sp.gov.br/basedados/tab mal/texto tab mal lam1.htm (consultado em 20/11/2002).

Taylor RM. Epidemiology. In: Stroder GK. Yellow Fever. McGraw-Hill. 1951. 42759.

Tesh RB, Guzman H, Travassos da Rosa APA, Vasconcelos PFC, Dias LB, Bunnell JE, Zhang H, Xiao SY. Experimental yellow fever vírus infection in the Golden Hamster (Mesocricetus auratus). 1 Virologic. Biochemical and Immunologic Studies. Journal of Infectious Diseases. 2001. 183: 1431-36.

Valle RR et al Captura de Primatas Não Humanos da espécie Alouatta caraya (HUMBOLDT, 1812) no município de Porto Rico, Paraná, Brasil, como ferramenta alternativa no controle de epizootias. XXXIX CONGRESSO DA SOCIEDADE DE MEDICINA TROPICAL (resumos) Volume 36 (suppl. I) Belém, 16 a 21 de Março de 2003. 
Vasconcelos PFC. Febre Amarela: reflexões sobre a doença, as perspectivas para o século XXI e o risco de urbanização. Revista Bras. Epidemiologia. 2002. Volume 5, $\mathrm{N}^{\circ} 2$.

Vasconcelos PFC. Febre Amarela. Revista da Sociedade Brás. de Méd. Trop. 2003. $36(2): 275-93$.

Waddell MB, Taylor RM. Studies on cyclic passage of yellow fever virus in South American mammals and mosquitoes: marmosets (Callithrix aurita) and cebus monkeys (Cebus versutus) in combination with Aedes aegypti and Haemagogus equinus. Am. J. Trop. Med. 1945. 25: 225-30.

Westaway EG, Briton MA, Gaidamovich SY, Horzinek MC, Igarashi A, Kaariainen L, Lvov DK. Porterfield JL, Russell PK, Trent DW. Flaviviridae. Intervirology. 1985. $24: 183-92$.

Wolfe ND. Kibourn AM, Karesh WB, Rahman HA, Bosi EJ. Silvatic Transmisson of Arboviruses Among Bornean Orangutans. Am. J. Trop. Med. Hyg. 64(5,6), 2001.

Woodall JP. The viruses isolated from arthropods at the East African Research Institute in the 26 years ending december. Proc. E. Afr.Acad. 1964. 2:141-46.

World Health Organization. Prevention and Control of yellow fever in Africa. Geneva. 1985. 
World Health Organization. Yellow Fever http:// www.who.ch/gpv-documents/ 1998 a.

World Health Organization. Dengue Bulletin, vol. 22, dec, 1998 b.

World Health Organization. Strengthening implementation of the global strategy for DF/DHF prevention e control. http:// www.who.int/vaccines-diseases/ research/virus 2 htm. 2001. 
Anexos 
Anexo 1 - Municípios com casos de Febre Amarela Silvestre e Epizootias, Brasil, 2003.

\begin{tabular}{|c|c|c|c|c|}
\hline $\mathbf{N}^{\mathbf{o}}$ & UF & Municípios & Situação do Município & $\begin{array}{c}\text { Mês de } \\
\text { ocorrência }\end{array}$ \\
\hline 1 & MG & Serro & Epizootia e caso de FAS & Janeiro \\
\hline 2 & MG & Alvorada de Minas & Caso de FAS & Janeiro \\
\hline 3 & MG & Sabinopólis & Caso de FAS & Janeiro \\
\hline 4 & MG & Senhora do Porto & Caso de FAS & Janeiro e fevereiro \\
\hline 5 & MG & Guanhaes & Caso de FAS & Janeiro \\
\hline 6 & RR & Canta & Epizootia & Janeiro \\
\hline 7 & RR & Mujacai & Epizootia & Janeiro \\
\hline 8 & RS & Santiago & Epizootia & Janeiro \\
\hline 9 & SP & Miguelopolis & Epizootia & Jan/ Fev/ Mar \\
\hline 10 & SP & Limeira do Oeste & Epizootia & Fevereiro \\
\hline 11 & MT & Nova Guarita & Epizootia & Fevereiro \\
\hline 12 & MT & Sto Antonio do Leverger & Epizootia & Fevereiro \\
\hline 13 & SP & Restinga & Epizootia & Março \\
\hline 14 & SP & Pedranopolis & Epizootia & Março \\
\hline 15 & MT & Cáceres & Epizootia e caso de FAS & Março/ Abril \\
\hline 16 & MT & $\begin{array}{c}\text { Vila Bela da Santíssima } \\
\text { Trindade }\end{array}$ & Epizootia & Março \\
\hline 17 & MG & Materlandia & Caso de FAS & Março \\
\hline 18 & MT & Tapurah & Caso de FAS & Abril \\
\hline 19 & RS & São Nicolau & Epizootia & Junho \\
\hline 20 & RS & Bossoroca & Epizootia & Junho \\
\hline 21 & $\overline{\mathrm{AC}}$ & Sena Madureira & Caso de FAS & Maio \\
\hline 22 & MT & Guaranta do Norte & Epizootia & Julho \\
\hline
\end{tabular}

Fonte: CIVES - Centro de Informação em Saúde para Viajantes - UFRJ

http:// www.cives.ufrj.br/informacao/fam/fam-br.html. 
Anexo 2 - Municípios com casos de Febre Amarela Silvestre e Epizootias, Brasil, 2004.

\begin{tabular}{|c|c|c|c|c|}
\hline $\mathbf{N}^{\mathbf{0}}$ & UF & Municípios & Situação do Município & $\begin{array}{c}\text { Mês de } \\
\text { ocorrência }\end{array}$ \\
\hline 1 & AM & Irandubao & Caso de FAS & Março \\
\hline 2 & PA & Parauapebas & $\begin{array}{c}\text { Caso de FAS e vetor } \\
\text { silvestre positivo }\end{array}$ & Abril \\
\hline 3 & RR & Amajari & Epizootia & Fevereiro \\
\hline 4 & PA & Vitoria do Xingu & Epizootia & Maio \\
\hline 5 & PA & Anapú & Epizootia & Maio \\
\hline 6 & AM & Itacoatiara & Caso de FAS & Junho \\
\hline 7 & GO & São Miguel do Passa Quatro & Epizootia & Julho \\
\hline 8 & GO & Goianápolis & Epizootia & Julho \\
\hline 9 & GO & Terezópolis de Goiás & Epizootia & Julho \\
\hline 10 & GO & Minaçu & Epizootia & Agosto \\
\hline 11 & GO & Santa Cruz de Goiás & Epizootia & Agosto \\
\hline 12 & TO & Ponte Alta do Tocantis & Epizootia & Setembro \\
\hline 13 & TO & Paranã & Epizootia & Setembro \\
\hline 14 & TO & Divinópolis & Epizootia & Setembro \\
\hline 15 & TO & Jaú do Tocantins & Epizootia & Setembro \\
\hline 16 & TO & Formoso do Araguaia & Epizootia & Outubro \\
\hline
\end{tabular}

Fonte: CIVES - Centro de Informação em Saúde para Viajantes - UFRJ

http:// www.cives.ufrj.br/informacao/fam/fam-br.html. 
Anexo 3 - Mapa dos municípios com casos confirmados e epizootias de febre amarela no Brasil, 2004.

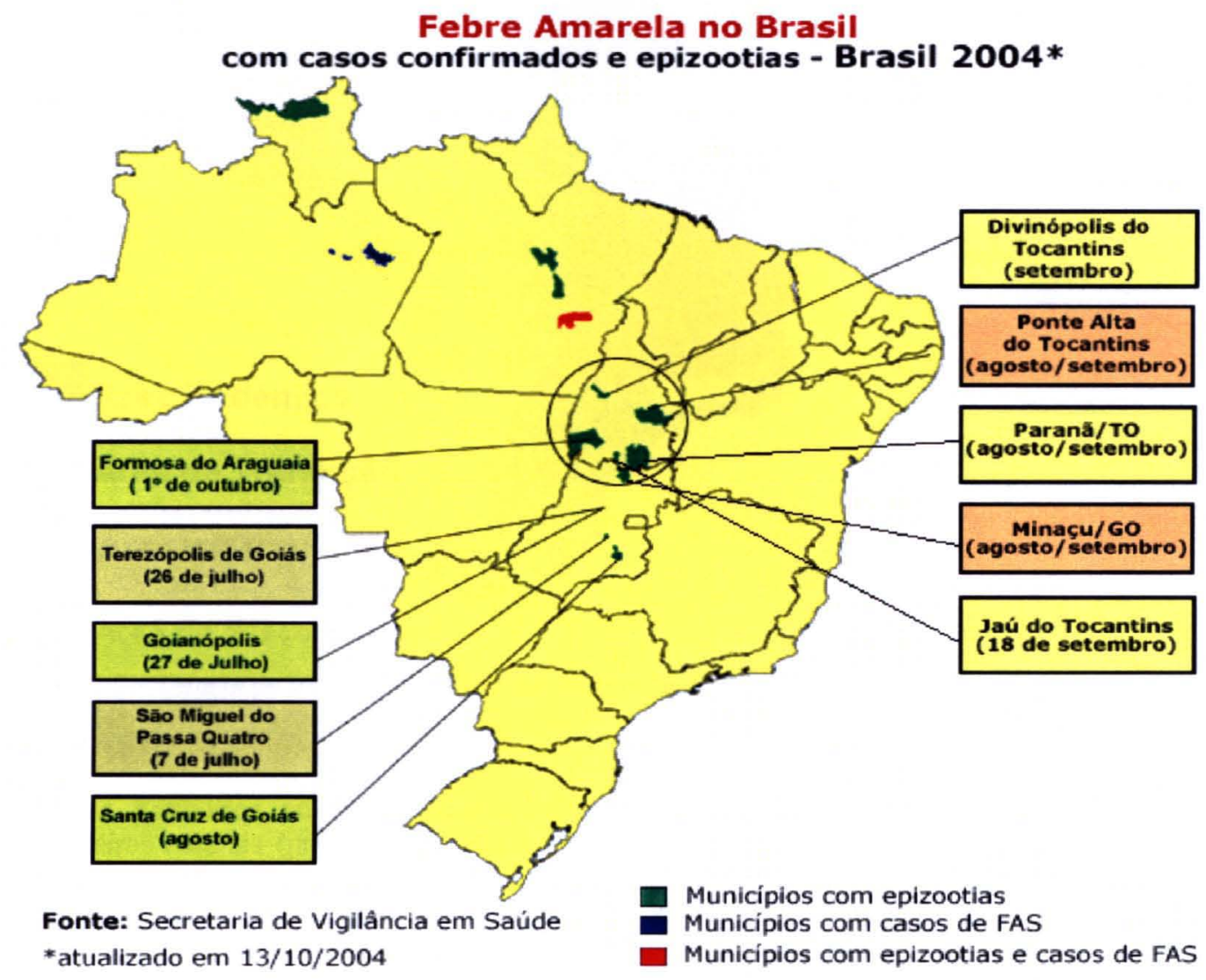


Anexo 4 - Mapa das áreas de Risco para Febre Amarela Silvestre no Brasil.

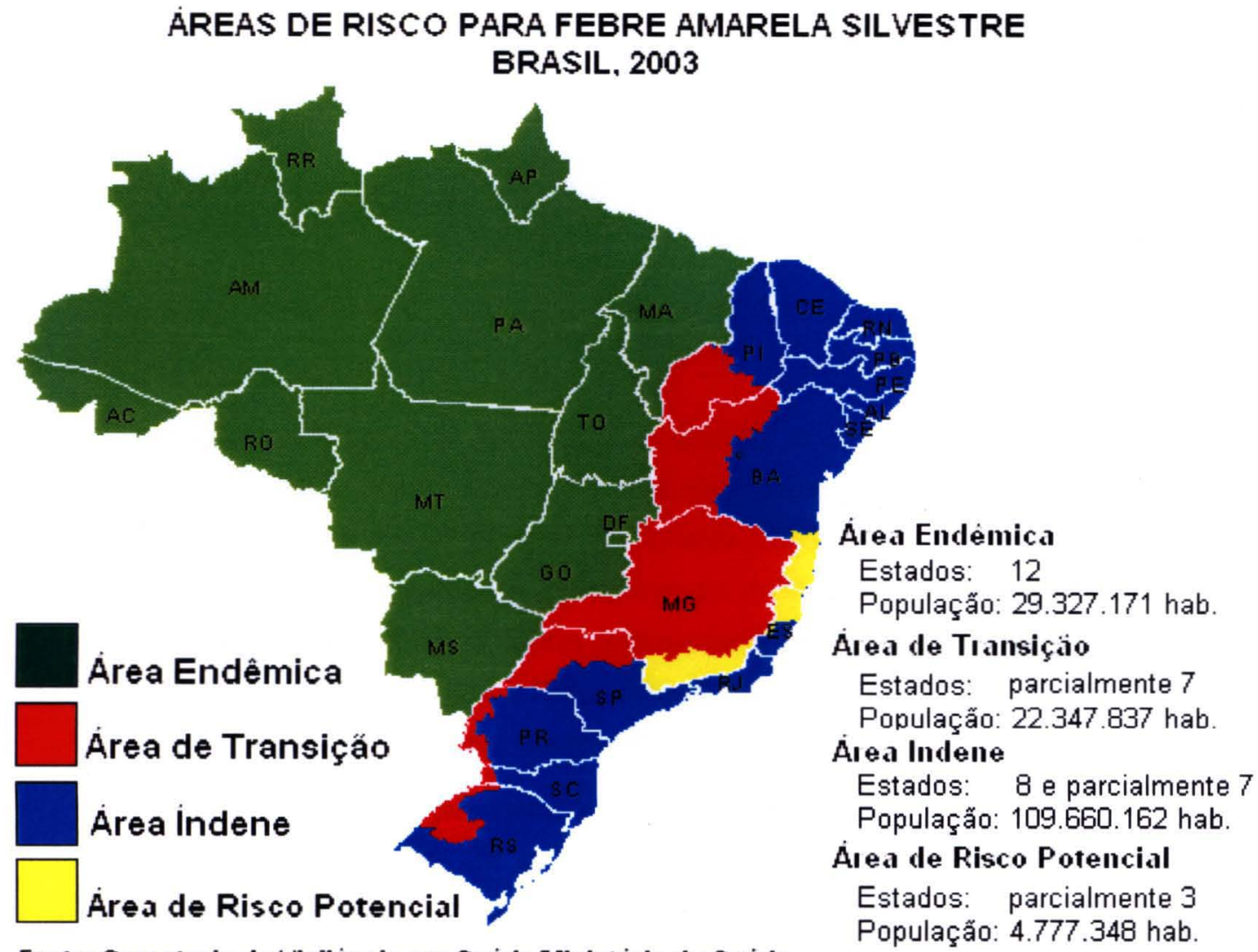

1) Área Enzoótica ou endêmica corresponde à área onde o vírus amarílico circula entre os hospedeiros naturais (principalmente macacos) e está presente a população de vetor. Os casos de febre amarela silvestre são quase sempre esporádicos e, às vezes, podem se manifestar em forma de pequenos surtos, como conseqüência da presença de pessoas não imunes. Abrange os Estados das regiões Norte, Centro-Oeste e o Estado do Maranhão (FUNASA, 2004).

2) Área Epizoótica ou de Transição, corresponde à área onde, no início do século XX, havia intensa circulação do vírus entre os hospedeiros naturais. No entanto, com o crescente processo de desmatamento na região, acredita-se que o nicho ecológico tenha sido alterado e nos últimos 30 anos a circulação do vírus tem sido evidenciada de forma esporádica no Estado de Minas Gerais, São Paulo e Paraná, Oeste de Santa Catarina e Noroeste do Rio Grande do Sul (FUNASA, 2004).

3) Área Indene corresponde à área onde não há circulação do vírus amarílico. Abrange os Estados das Regiões Nordeste, Sudeste e Sul. Compreende 14 Estados, sendo que 7 deles estão parcialmente inseridos em área de Risco para Circulação do Vírus (FUNASA, 2004).

4) Área de Risco Potencial corresponde a zonas contíguas às áreas de transição onde houve identificação recente da presença do vírus, tem ecossistemas semelhantes e apresenta maior risco para circulação do vírus. Fazem parte dessa nova área: Centro-Norte do Estado do Espírito Santo, a partir do Vale do Canaã, em direção Norte, área de influência da Bacia do Rio Doce; Sul da Bahia, abaixo do Rio Jequitinhonha e o Sul de Minas Gerais (FUNASA, 2004). 
Anexo 5 - Carta de Autorização do IBAMA

Säroatica c

Três Lagoas, 26 de novembro de 2003.

DECLARAMOS, para os devidos fins, que as amostras de sangue de animais silvestres utilizadas para realização do projeto de doutorado da pesquisadora Ana Maria Ribeiro de Castro Duarte, sob orientação do Prof. Dr. Almério de Castro Gomes, do Departamento de Epidemiologia da Faculdade de Saúde Pública da Universidade de São Paulo, foram cedidas pela CESP a partir de material coletado pelo Programa de Resgate e Relocação de Fauna Silvestre, durante a formação do reservatório da UHE Eng. Sérgio Motta.

Foram utilizadas pela pesquisadora amostras de sangue de 590 exemplares do bugio Alouatta caraya, 22 exemplares de macaco prego Cebus apella, seis exemplares de cateto Tayassu tajacu, dois exemplares de ouriço Coendou sp., um exemplar de capivara Hydrochaeris hydrochaeris, um exemplar de jacaré Caiman latirostris e um exemplar de tatu Dasypus novemcinctus. A captura dos animais e as coletas de amostras foram devidamente autorizadas pelo Instituto Brasileiro do Meio Ambiente e dos Recursos Naturais Renováveis - IBAMA.

$\mathrm{Na}$ pesquisa sobre malária foram realizados exames parasitológicos para identificação de infecçōes por plasmóides (exames de gota espessa, esfregaço sangüineo e PCR) e testes sorológicos para detecção de anticorpos contra malária (teste de ELISA para verificação de anticorpos contra formas infectantes de plasmódio teste de imunofluorescência indireta para verificação de anticorpos

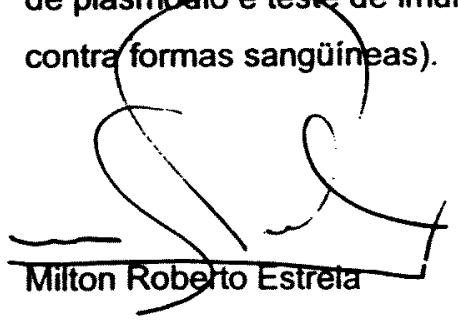

Divisão de Implantação e Manutenção de Programas Ambientais

Gerente 
Anexo 6 - Valores expressos em absorbância $(405 \mathrm{~nm})$ para reação de ELISA utilizando para cálculo do Limiar reatividade (“cut-off”). Reação com antígeno de febre amarela de soros humanos $(\mathrm{N}=12)$ para cálculo do Limiar reatividade ("cutoff'). Diluição dos soros: 1:40, conjugado anti-IgG humano: 1:3000 (Sigma - A8419). Substrato ABTS. Valores expressos em absorbância (405nm).

\begin{tabular}{c|c}
\hline \multirow{2}{*}{ Amostras de Soros } & Absorbâncias \\
\hline 01 & 0,637 \\
02 & 0,588 \\
03 & 0,424 \\
04 & 0,453 \\
05 & 0,529 \\
06 & 0,612 \\
07 & 0,770 \\
08 & 0,701 \\
09 & 0,048 \\
10 & 0,051 \\
11 & 0,061 \\
12 & 0,059 \\
\hline
\end{tabular}


Anexo 7 - Padronização da diluição de fluido ascítico anti-febre amarela utilizando soro controle positivo Humano.

\begin{tabular}{|c|c|c|c|c|c|c|}
\hline Diluição & & & An & eno & & \\
\hline Fluido Ascítico & $1: 20$ & $1: 40$ & $1: 80$ & $1: 160$ & $1: 320$ & $1: 640$ \\
\hline $1: 200$ & 0,638 & 0,633 & 0,535 & 0,510 & 0,507 & 0,503 \\
\hline $1: 400$ & 0,596 & 0,588 & 0,886 & 0,490 & 0,485 & 0,472 \\
\hline $1: 800$ & 0,579 & 0,526 & 0,468 & 0,460 & 0,444 & 0,379 \\
\hline 1: 1640 & 0,500 & 0,495 & 0,458 & 0,456 & 0,420 & 0,345 \\
\hline
\end{tabular}

Diluição dos soros humanos: 1:40, conjugado Anti- IgG-humano (Sigma A: 8419) utilizado na concentração de 1:3000. Substrato: ABTS. Leitura das Densidades óticas em 405 nm. Aparelho Multiscan. 
Anexo 8 - Padronização da diluição de fluido ascítico anti-febre amarela utilizando soro controle negativo Humano.

\begin{tabular}{|c|c|c|c|c|c|c|}
\hline Diluição & & & An & eno & & \\
\hline Fluido Ascítico & $1: 20$ & $1: 40$ & $1: 80$ & $1: 160$ & $1: 320$ & $1: 640$ \\
\hline $1: 200$ & 0,090 & 0,085 & 0,072 & 0,065 & 0,050 & 0,043 \\
\hline $1: 400$ & 0,070 & 0,065 & 0,062 & 0,053 & 0,048 & 0,037 \\
\hline $1: 800$ & 0,037 & 0,030 & 0,029 & 0,025 & 0,018 & 0,015 \\
\hline 1: 1640 & 0,022 & 0,016 & 0,012 & 0,009 & 0,004 & 0,001 \\
\hline
\end{tabular}

Diluição dos soros humanos: 1:40, conjugado Anti- IgG-humano (Sigma A: 8419) utilizado na concentração de 1:3000. Substrato: ABTS. Leitura das Densidades óticas em $405 \mathrm{~nm}$. Aparelho Multiscan. 
Anexo 9 - Titulação de Conjugado Anti- Humano (IgG) com soro humano positivo.

\begin{tabular}{c|c|c|c}
\hline & Diluição & \multicolumn{3}{|c}{ Conjugado } \\
Soros & $(1: 1000)$ & $(1: 2000)$ & $(1: 3000)$ \\
\hline $1: 20$ & 0,938 & 0,907 & 0,797 \\
\hline $1: 40$ & 0,881 & 0,879 & 0,791 \\
\hline $1: 80$ & 0,863 & 0,789 & 0,553 \\
\hline $1: 160$ & 0,831 & 0,752 & 0,505 \\
\hline $1: 320$ & 0,806 & 0,659 & 0,481 \\
\hline $1: 640$ & 0,773 & 0,538 & 0,410 \\
\hline
\end{tabular}

Conjugado Anti- Monkey (IgG) Sigma A:2054 com peroxidase 1:3000; fluido ascítico: 1:200; antígeno 1:320. Substrato: ABTS. Leitura das Densidades óticas em $405 \mathrm{~nm}$. Aparelho Multiscan. 
Anexo 10 - Titulação de Conjugado Anti- Humano (IgG) com soro humano negativo.

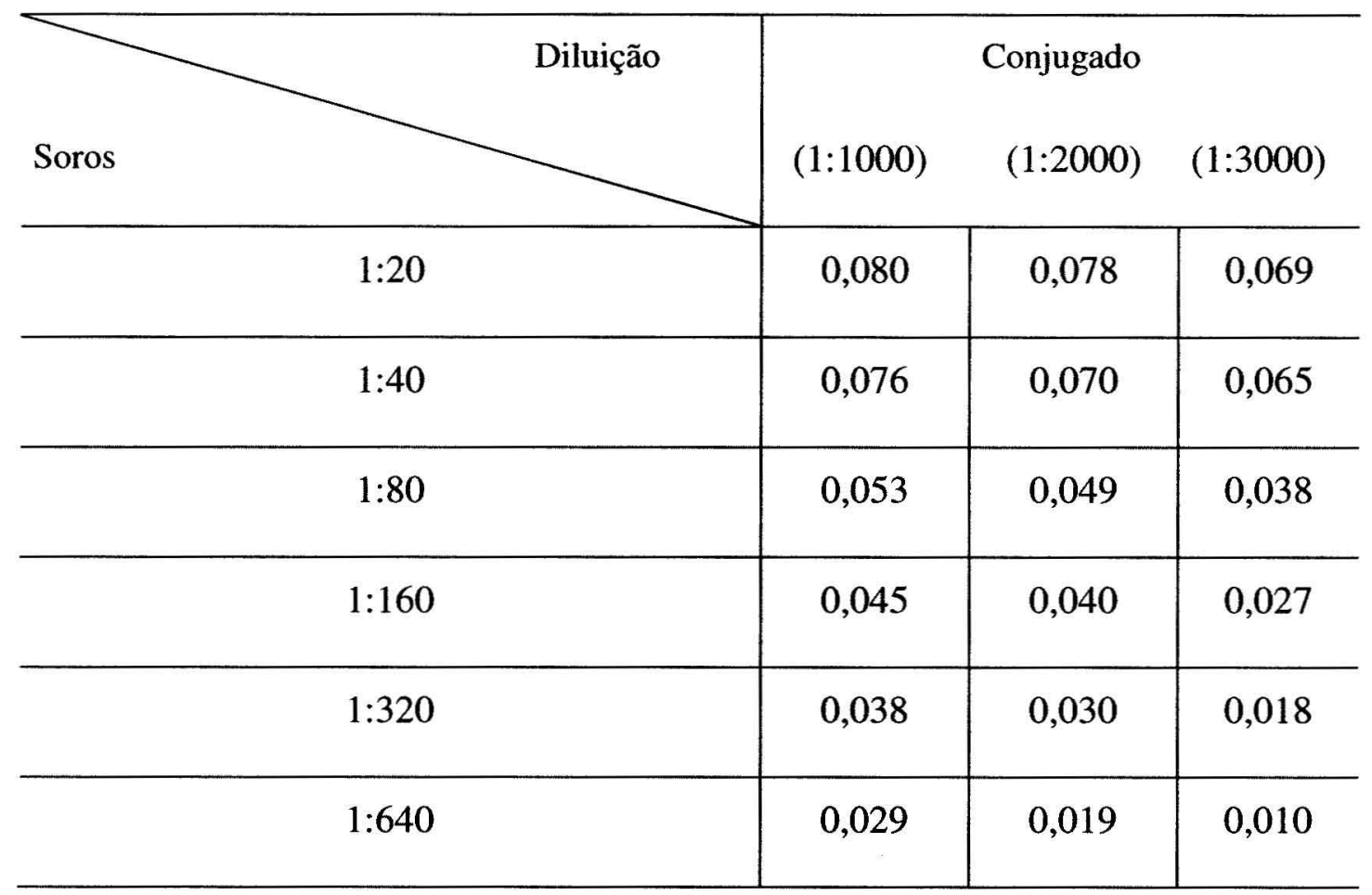

Conjugado Anti- Monkey (IgG) Sigma A:2054 com peroxidase 1:3000; fluido ascítico: 1:200; antígeno 1:320. Substrato: ABTS. Leitura das Densidades óticas em $405 \mathrm{~nm}$. Aparelho Multiscan. 
Anexo 11 - Soluções Utilizadas para realizações do teste de ELISA.

\section{PBS (solução mãe - concentrada em $10 \mathrm{X}$ )}

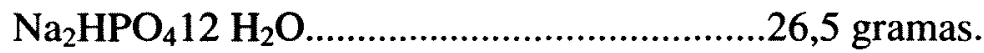

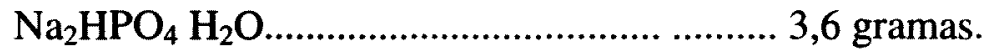

NaCL........................................................81,7 gramas.

Diluir em $1000 \mathrm{ml}$ de água destilada, utilizar para fazer o tampão de lavagem.

2. Tampão PBS - Tween 20 (solução de lavagem).

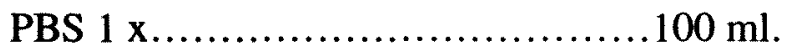

Tween $20 \ldots \ldots \ldots \ldots \ldots \ldots \ldots \ldots . . . . . . . .6,5 \mathrm{ml}$.

Diluir em $900 \mathrm{ml}$ de água destilada, utilizar para lavagem das placas com os testes.

\section{Solução para Diluição dos soros.}

Leite em pó desnatado Molico (Nestlé) ..............2,5 gramas.

Tampão PBS - Tween $20 \ldots \ldots \ldots \ldots \ldots \ldots \ldots \ldots \ldots . . .300 \mathrm{ml}$.

\section{Solução de Bloqueio.}

Leite em pó desnatado Molico (Nestlé) ................5,0 gramas.

Tampão PBS - Tween 20.......................300 ml.

\section{Tampão Carbonato Bicarbonato.}

2 comprimidos diluídos em $100 \mathrm{ml}$ de água bidestilada, utilizado para sensibilizar a placa com fluido ascítico. 
Anexo 12 - Reagentes e Materiais Utilizados

* Cloreto de Sódio

* Fosfato Dibásico de Sódio (Na2HPO4 $\mathrm{H}_{2} \mathrm{O}$ ) Merck.

* Fosfato Monobásico de Sódio (Na2HPO4 $12 \mathrm{H}_{2} \mathrm{O}$ ) Merck.

* Leite em pó desnatado Molico (Nestlé).

* Tween 20 (Polyoxyethylenesorbitan monolaurate) lote: 33HO250 Merck.

* Microplacas de 96 cavidades (NUNC ß).

* Ponteiras descartáveis.

* Pipetas de varias diluições.

* Conjugado anti-humano IgG Sigma (A-8419).

* Conjugado antimacaco Rhesus IgG (Sigma A-2054).

* Peroxidase substrate (solução A) e Peroxidase (H2O2) (solução B). Kirkegaard \& Perry Laboratories Inc. 
Anexo 13 - Resultado da sorologia com 570 amostras de macacos da espécie Alouatta caraya

\begin{tabular}{|c|c|}
\hline Amostras de Soros & Densidade Óptica \\
\hline 01 & 0,056 \\
\hline 02 & 0,074 \\
\hline 03 & 0,094 \\
\hline 04 & 0,041 \\
\hline 05 & 0,045 \\
\hline 06 & 0,055 \\
\hline 07 & 0,065 \\
\hline 08 & 0,044 \\
\hline 09 & 0,070 \\
\hline 10 & 0,031 \\
\hline 11 & 0,090 \\
\hline 12 & 0,036 \\
\hline 13 & 0,037 \\
\hline 14 & 0,033 \\
\hline 15 & 0,070 \\
\hline 16 & 0,048 \\
\hline 17 & 0,042 \\
\hline 18 & 0,047 \\
\hline 19 & 0,097 \\
\hline 20 & 0,069 \\
\hline 21 & 0,035 \\
\hline 22 & 0,062 \\
\hline 23 & 0,034 \\
\hline 24 & 0,047 \\
\hline 25 & 0,070 \\
\hline 26 & 0,070 \\
\hline 27 & 0,048 \\
\hline 28 & 0,011 \\
\hline 29 & 0,032 \\
\hline 30 & 0,040 \\
\hline 31 & 0,061 \\
\hline 32 & 0,020 \\
\hline 33 & 0,027 \\
\hline 34 & 0,003 \\
\hline 35 & 0,046 \\
\hline 36 & 0,007 \\
\hline 37 & 0,078 \\
\hline 38 & 0,021 \\
\hline 39 & 0,061 \\
\hline 40 & 0,088 \\
\hline 41 & 0,104 \\
\hline 42 & 0,029 \\
\hline 43 & 0,108 \\
\hline 44 & 0,091 \\
\hline 45 & 0,102 \\
\hline 46 & 0,079 \\
\hline 47 & 0,066 \\
\hline 48 & 0,027 \\
\hline 49 & 0,034 \\
\hline 50 & 0,036 \\
\hline 51 & 0,067 \\
\hline 52 & 0,056 \\
\hline 53 & 0,081 \\
\hline 54 & 0,094 \\
\hline 55 & 0,034 \\
\hline
\end{tabular}




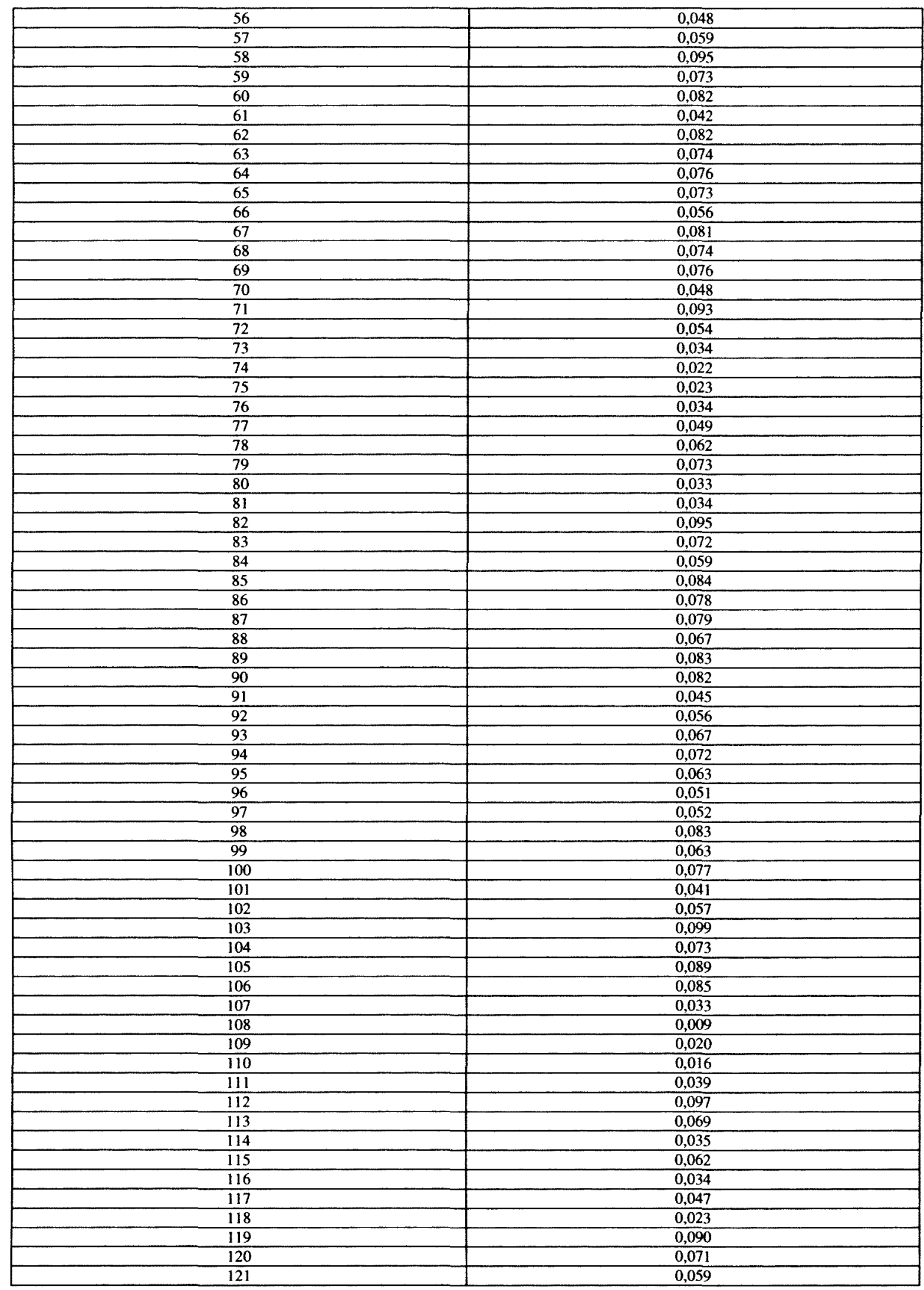




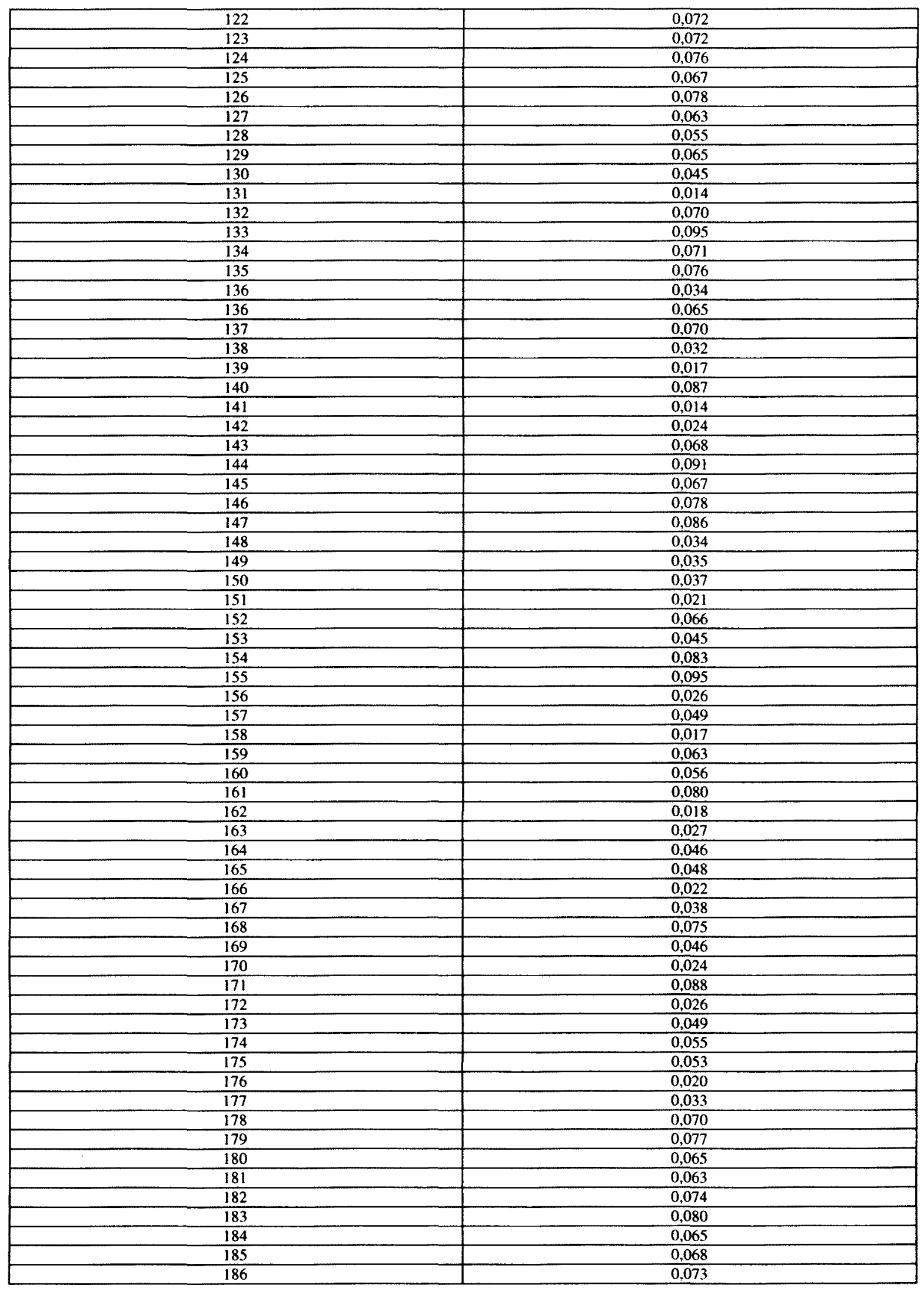




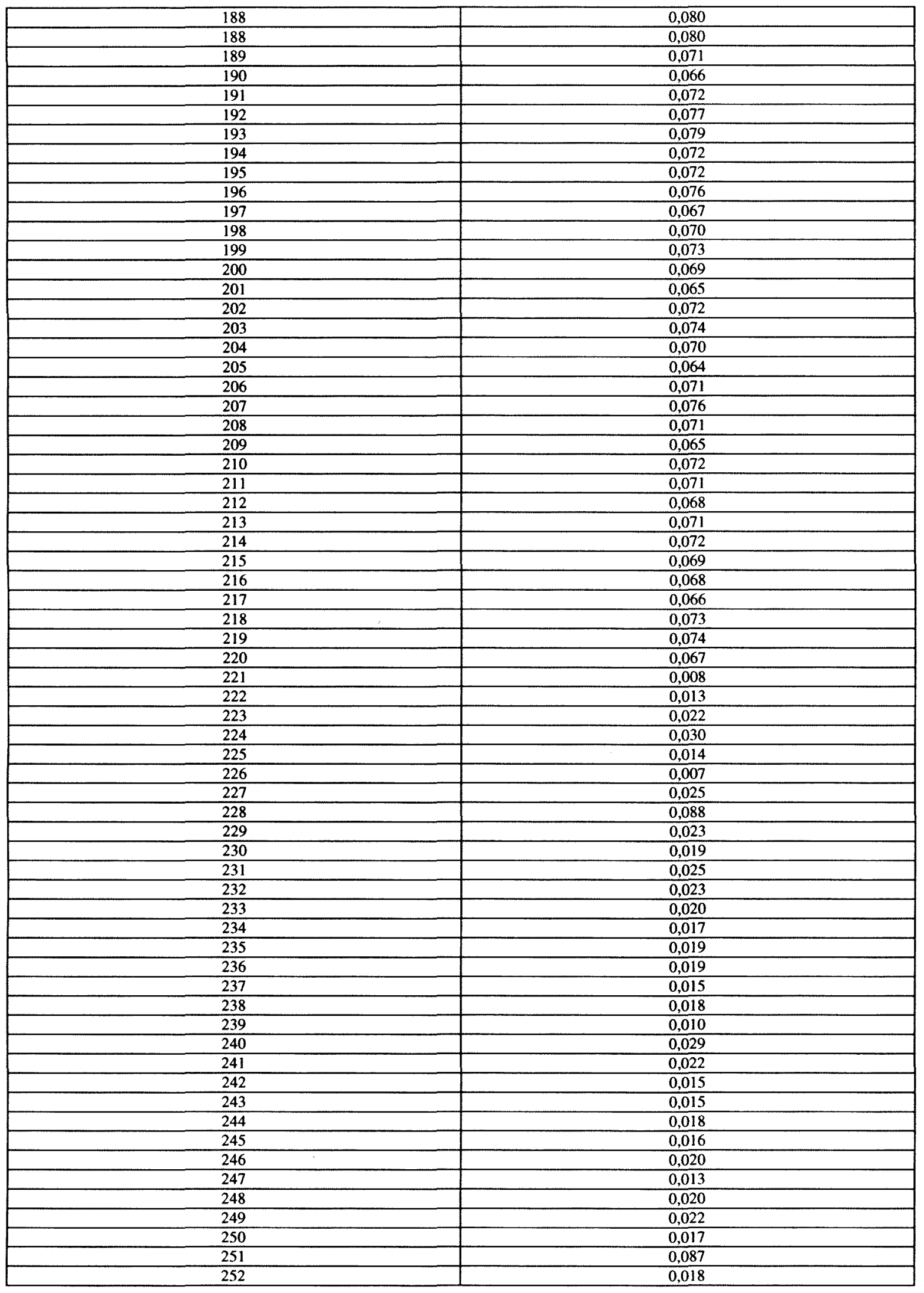




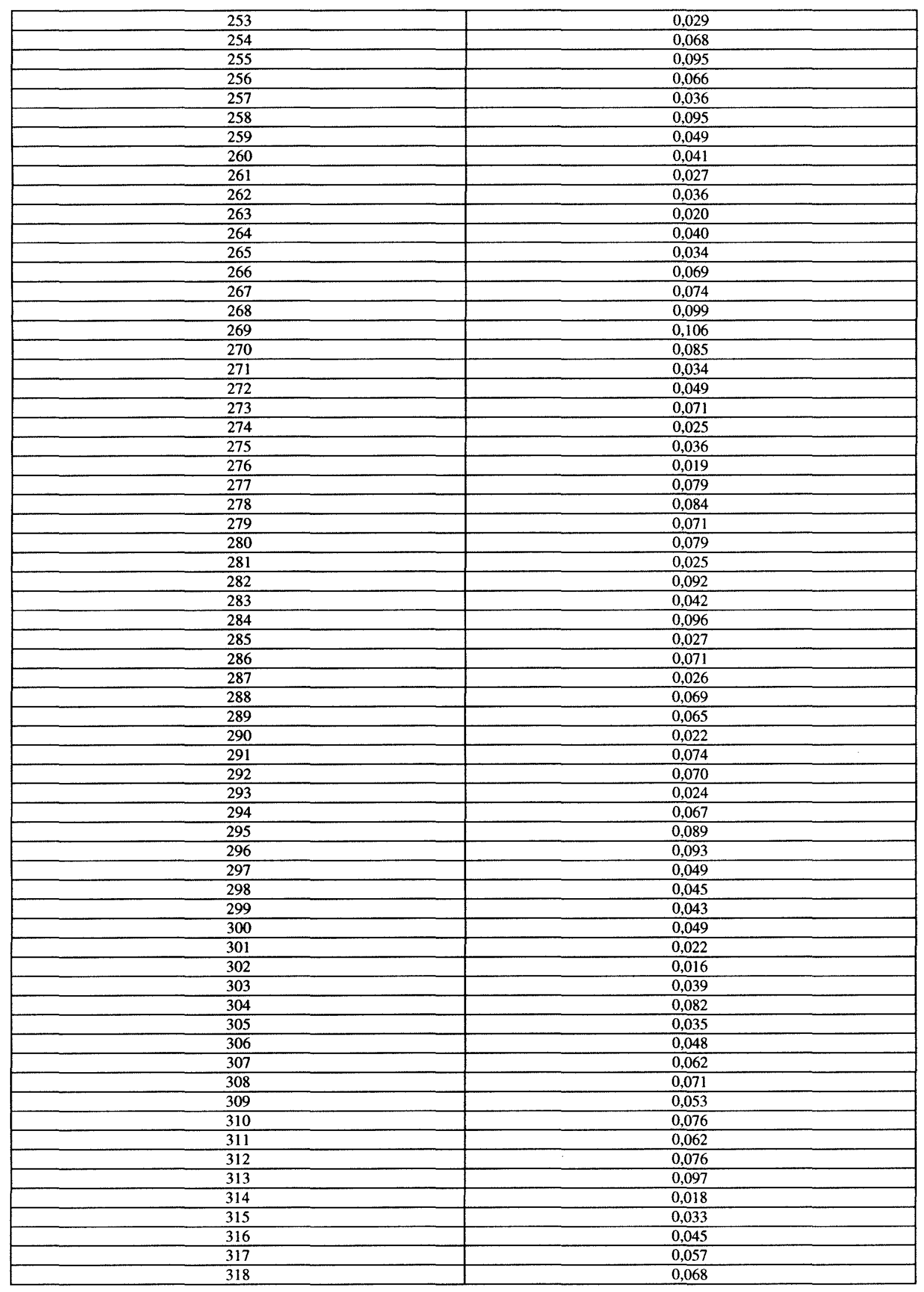




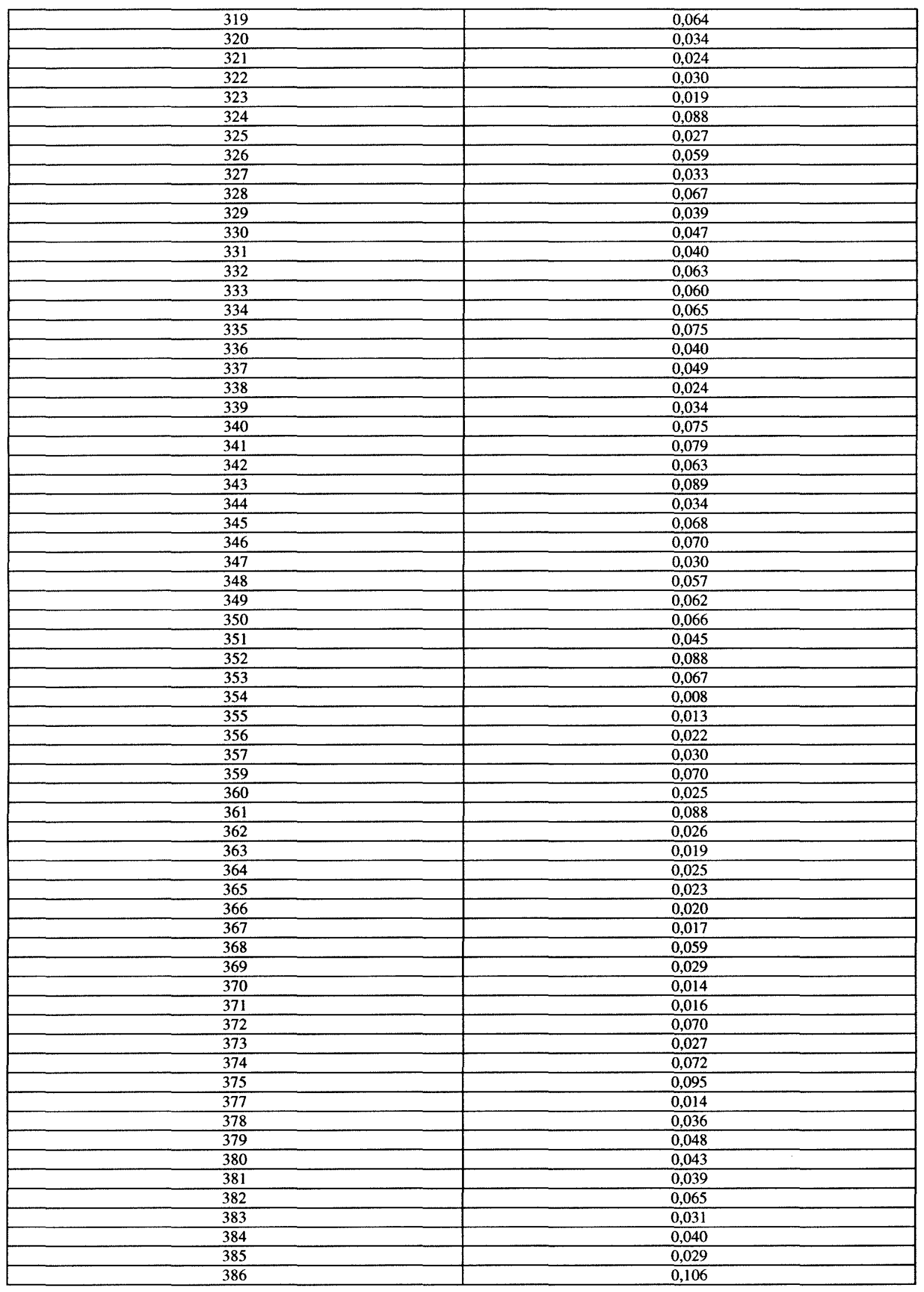




\begin{tabular}{|c|c|}
\hline 387 & 0,090 \\
\hline 388 & 0,093 \\
\hline 389 & 0,015 \\
\hline 390 & 0,037 \\
\hline 391 & 0,084 \\
\hline 392 & 0,052 \\
\hline 393 & 0,055 \\
\hline 394 & 0,063 \\
\hline 395 & 0,052 \\
\hline 396 & 0,034 \\
\hline 397 & 0,024 \\
\hline 398 & 0,029 \\
\hline 399 & 0,039 \\
\hline 400 & 0,049 \\
\hline 401 & 0,058 \\
\hline 402 & 0,068 \\
\hline 403 & 0,071 \\
\hline 404 & 0,094 \\
\hline 405 & 0.089 \\
\hline 406 & 0,084 \\
\hline 407 & 0,029 \\
\hline 408 & 0,036 \\
\hline 409 & 0,048 \\
\hline 410 & 0,056 \\
\hline 411 & 0,078 \\
\hline 412 & 0,068 \\
\hline 413 & 0,072 \\
\hline 414 & 0,038 \\
\hline 415 & 0,048 \\
\hline 416 & 0,045 \\
\hline 418 & 0,037 \\
\hline 419 & 0,071 \\
\hline 420 & 0,013 \\
\hline 421 & 0,024 \\
\hline 422 & 0,045 \\
\hline 423 & 0,017 \\
\hline 424 & 0,027 \\
\hline 425 & 0,034 \\
\hline 426 & 0,019 \\
\hline 427 & 0,029 \\
\hline 428 & 0,015 \\
\hline 429 & 0,026 \\
\hline 430 & 0,028 \\
\hline 431 & 0,023 \\
\hline 432 & 0,030 \\
\hline 433 & 0,038 \\
\hline 434 & 0,049 \\
\hline 436 & 0,014 \\
\hline 437 & 0,029 \\
\hline 438 & 0,016 \\
\hline 439 & 0,018 \\
\hline 440 & 0,038 \\
\hline 441 & 0,090 \\
\hline 442 & 0,101 \\
\hline 443 & 0,039 \\
\hline 444 & 0,056 \\
\hline 445 & 0,036 \\
\hline 446 & 0,067 \\
\hline 447 & 0,047 \\
\hline 448 & 0,037 \\
\hline 449 & 0,019 \\
\hline 450 & 0,038 \\
\hline 451 & 0,038 \\
\hline 452 & 0,049 \\
\hline 453 & 0,040 \\
\hline 454 & 0,045 \\
\hline
\end{tabular}




\begin{tabular}{|c|c|}
\hline 455 & 0,039 \\
\hline 456 & 0,036 \\
\hline 457 & 0,048 \\
\hline 458 & 0,049 \\
\hline 459 & 0,059 \\
\hline 460 & 0,047 \\
\hline 461 & 0,058 \\
\hline 462 & 0,067 \\
\hline 463 & 0,077 \\
\hline 464 & 0,028 \\
\hline 465 & 0,038 \\
\hline 466 & 0,067 \\
\hline 467 & 0,037 \\
\hline 468 & 0,013 \\
\hline 469 & 0,038 \\
\hline 470 & 0,074 \\
\hline 471 & 0,080 \\
\hline 472 & 0,064 \\
\hline 473 & 0,012 \\
\hline 474 & 0,017 \\
\hline 475 & 0,076 \\
\hline 476 & 0,077 \\
\hline 477 & 0,074 \\
\hline 478 & 0,034 \\
\hline 479 & 0,045 \\
\hline 480 & 0,027 \\
\hline 481 & 0,068 \\
\hline 482 & 0,066 \\
\hline 483 & 0,049 \\
\hline 484 & 0,068 \\
\hline 485 & 0,053 \\
\hline 486 & 0,037 \\
\hline 487 & 0,043 \\
\hline 488 & 0,011 \\
\hline 489 & 0,016 \\
\hline 490 & 0,014 \\
\hline 491 & 0,045 \\
\hline 492 & 0,047 \\
\hline 493 & 0,085 \\
\hline 494 & 0,069 \\
\hline 495 & 0,012 \\
\hline 496 & 0,023 \\
\hline 497 & 0,034 \\
\hline 498 & 0,056 \\
\hline 499 & 0,090 \\
\hline 500 & 0,036 \\
\hline 501 & 0,037 \\
\hline 502 & 0,033 \\
\hline 503 & 0,070 \\
\hline 504 & 0,068 \\
\hline 505 & 0,046 \\
\hline 506 & 0,047 \\
\hline 507 & 0,097 \\
\hline 508 & 0,019 \\
\hline 509 & 0,022 \\
\hline 510 & 0,092 \\
\hline 511 & 0,036 \\
\hline 512 & 0,045 \\
\hline 513 & 0,028 \\
\hline 514 & 0,063 \\
\hline 515 & 0,055 \\
\hline 516 & 0,065 \\
\hline 517 & 0,030 \\
\hline 518 & 0,095 \\
\hline 519 & 0,049 \\
\hline 520 & 0,041 \\
\hline
\end{tabular}




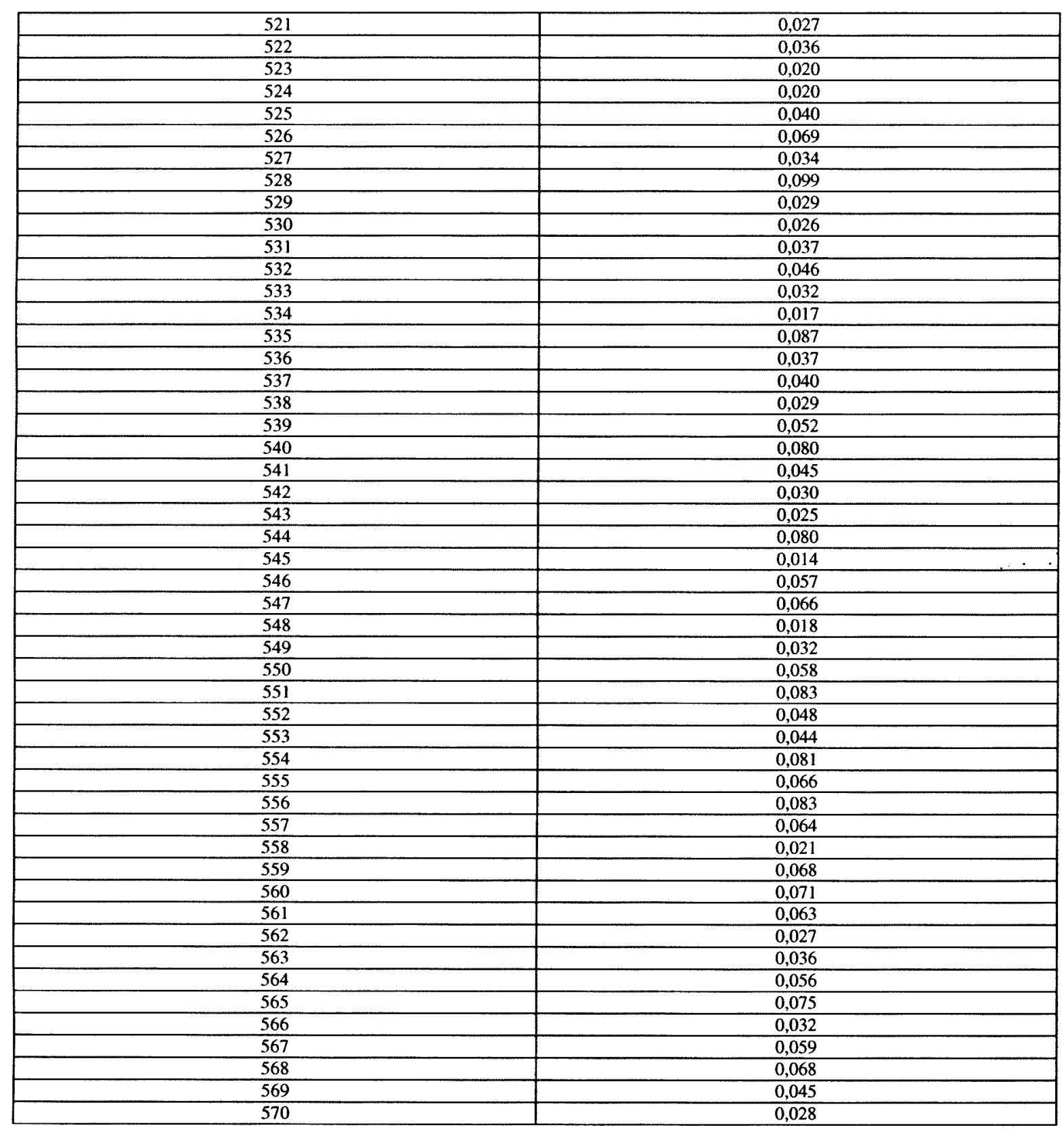

